\title{
Resveratrol Enhances Neurite Outgrowth and Synaptogenesis Via Sonic Hedgehog Signaling Following Oxygen-Glucose Deprivation/Reoxygenation Injury
}

\author{
Fanren Tang Shuang Guo Hongyan Liao Pingping Yu Li Wang \\ Xiaosong Song Jixiang Chen Qin Yang \\ Department of Neurology, the First Affiliated Hospital of Chongqing Medical University, Chongqing, \\ China
}

\section{Key Words}

Resveratrol • Neuron • Sonic hedgehog signaling • Neurite outgrowth • Synaptogenesis • Cyclopamine $\cdot$ Purmophamine $\cdot$ Sirtinol $\cdot$ Sirt1

\begin{abstract}
Background/Aims: Neurite outgrowth and synaptogenesis are critical steps for functional recovery after stroke. Resveratrol promotes neurite outgrowth and synaptogenesis, but the underlying mechanism is not well understood, although the Sonic hedgehog (Shh) signaling pathway may be involved. Given that resveratrol activates sirtuin (Sirt)1, the present study examined whether this is mediated by Shh signaling. Methods: Primary cortical neuron cultures were pretreated with drugs before oxygen-glucose deprivation/reoxygenation $(\mathrm{OGD} / \mathrm{R})$. Cell viability and apoptosis were evaluated with Cell Counting Kit 8 and by terminal deoxynucleotidyl transferase dUTP nick end labeling, respectively. Neurite outgrowth and synaptogenesis were assessed by immunocytochemistry and western blotting, which was also used to examine the expression of Sirt1 and Shh signaling proteins. Results: Resveratrol and the Smoothened (Smo) agonist purmophamine, which activates Shh signaling, increased viability, reduced apoptosis, and stimulated neurite outgrowth after OGD/R injury. Moreover, the expression of growth-associated protein(GAP)-43, synaptophysin, Shh, Patched (Ptc)- 1 , Smo, glioma-associated oncogene homolog (Gli)-1, and Sirt1 were upregulated under these conditions. These effects were reversed by treatment with the Smo inhibitor cyclopamine, whereas the Sirt1 inhibitor sirtinol reduced the levels of Shh, Ptc-1, Smo, and Gli-1. Conclusions: Resveratrol reduces neuronal injury following OGD/R injury and enhances neurite outgrowth and synaptogenesis by activating Shh signaling, which in turn induces Sirt1.
\end{abstract}




\section{Cellular Physiology Cell Physiol Biochem 2017;43:852-869 \begin{tabular}{ll|l}
\hline DOI: 10.1159/000481611 & $\begin{array}{l}\text { C } 2017 \text { The Author(s). Published by S. Karger AG, Basel } \\
\text { www.karger.com/cpb }\end{array}$
\end{tabular} \\ Tang et al.: Resveratrol Enhances Neurite Outgrowth and Synaptogenesis Via Activating the Shh Signaling Pathway}

\section{Introduction}

Ischemic stroke is a leading cause of disability after which surviving neurons in the peri-infarct region form new connections through neurite outgrowth and synaptogenesis as part of the recovery process [1].

Resveratrol (trans-3, 5,4'-trihydroxystilbene) is a naturally occurring polyphenolic phytoalexin derived from plants such as Polygonum cuspidatum, grapes, Semen cassiae, and mulberries, among others [2]. It has anti-aging, -apoptotic, -tumorigenic, -oxidant, and -inflammatory properties [3-6] as well as neuroprotective effects against stroke, Alzheimer's disease, and Parkinson's disease [6-10]. In addition, resveratrol prevents axonal degeneration after injury and promotes neurite outgrowth and synaptogenesis [11-13]. We previously reported that resveratrol pretreatment reduced cerebral ischemic injury, thereby improving neurological function in vivo $[14,15]$, and promoted neural stem cell (NSC) proliferation after oxygen-glucose deprivation/reoxygenation (OGD/R) injury in vitro [16, 17].

The canonical Sonic hedgehog (Shh) signaling pathway includes Shh ligand, patched (Ptc) and Smoothened (Smo) receptors, and glioma-associated oncogene homolog (Gli) transcription factors (Gli-1, -2, and -3) $[18,19]$. Shh binds to the Ptc receptor at the cell surface, relieving Smo inhibition and inducing its translocation to the primary cilium, thereby activating Gli transcription factors and downstream effectors of the Shh pathway $[18,19]$. Shh signaling plays a critical role in the patterning of the central nervous system, regulation of stem cell behavior, axonal growth and guidance, and neurite outgrowth and synaptogenesis in the developing and adult brains $[18,19]$. Shh signaling is activated under pathological conditions such as stroke and prevents oxidative injury and apoptosis while promoting neurogenesis, oligodendrogenesis, and axonal remodeling and improving neurological function [20-22]. Our earlier study demonstrated that resveratrol treatment reduces cerebral ischemic injury and improves functional outcome after stroke in vivo, enhances NSC proliferation in vitro following OGD/R injury, and induces the differentiation of bone mesenchymal stem cells into neuronal-like cells via activation of Shh signaling [15, $17,23]$.

Sirtuin (Sirt) $l$ is a nicotinamide adenine dinucleotide-dependent protein deacetylase that is activated by resveratrol to inhibit aging, provide neuroprotection, and stimulate neurogenesis [24-30]. A Sirt1 complex was found to inhibit Shh signaling in normal and oncogenic neural development [31]; however, it is unknown whether this occurs following stroke.

In the present study, we investigated whether Shh signaling mediated the effects of resveratrol on OGD/R injury via Sirt1 in primary cortical neuron model of OGD/R injury. We found that resveratrol pretreatment increased neuronal survival, inhibited apoptosis, and enhanced neurite outgrowth and synaptogenesis, which was associated with activation of Shh signaling and upregulation of Sirt1. These results indicate that resveratrol treatment is a novel therapeutic strategy for mitigating neuronal damage following stroke.

\section{Materials and Methods}

\section{Reagents}

Neurobasal medium, B-27, and Dulbecco's Modified Eagle's Medium (DMEM)/F12 were purchased from Gibco (Grand Island, NY, USA). Penicillin/streptomycin, L-glutamine, and D-Hank's solution were from HyClone (Logan, UT, USA). Papain and resveratrol (purity: 99\%) were from Sigma-Aldrich (St. Louis, MO, USA). Fetal bovine serum (FBS) was from Zhejiang Tianhang Biological Technology Stock Co. (Zhejiang, China). Cell Counting Kit (CCK)-8 was from Dojindo Laboratories (Kumamoto, Japan). The terminal deoxynucleotidyl transferase dUTP-mediated nick end labeling (TUNEL) Apoptosis Detection kit was from Roche (Basel, Switzerland). Cyclopamine, purmorphamine, and sirtinol (purity: 99\%) were from Cayman Chemical (Ann Arbor, MI, USA). Monoclonal antibodies against mouse anti-microtubule-associated protein (MAP) 2 and neuronal class III $\beta$-tubulin (TuJ1) were from Millipore (Billerica, MA, USA). Monoclonal rabbit 


\section{Cellular Physiology Cell Physiol Biochem 2017;43:852-869 \\ \begin{tabular}{ll|l} 
and Biochemistry & $\begin{array}{l}\text { DOI: 10.1159/000481611 } \\
\text { Published online: September 28, } 2017\end{array}$ & $\begin{array}{l}\text { C } 2017 \text { The Author(s). Published by S. Karger AG, Basel } \\
\text { www.karger.com/cpb }\end{array}$ \\
\hline
\end{tabular} \\ Tang et al.: Resveratrol Enhances Neurite Outgrowth and Synaptogenesis Via Activating the Shh Signaling Pathway}

anti-growth-associated protein (GAP)43 and anti-synaptophysin (SYP), monoclonal mouse anti-Sirt1, and polyclonal rabbit anti-Shh, -Ptch-1, -Smo, and -Gli-1 antibodies were from Abcam (Cambridge, UK). Rabbit anti-glyceraldehyde 3-phosphate dehydrogenase (GAPDH) antibodies were from Beyotime Institute of Biotechnology (Shanghai, China) and Goodhere Biotechnology (Hangzhou, China). Normal goat serum (10\%), and goat anti-rabbit Alexa Fluor 488 and anti-mouse Alexa Fluor 594 were from Beijing Zhongshan Golden Bridge Biotechnology (Beijing, China). Radioimmunoprecipitation assay (RIPA) lysis buffer, phenylmethanesulfonyl fluoride (PMSF), and 4,6-diamidino-2-phenylindole (DAPI) were from Beyotime Institute of Biotechnology (Jiangsu, China). Peroxidase-conjugated affiniPure goat anti-rabbit and antimouse IgG were from Proteintech Biotechnology (Wuhan, China).

\section{Primary cortical neuron culture}

Neonatal male and female Sprague-Dawley rats (1 day old) provided by the Experimental Animal Center of Chongqing Medical University (Chongqing, China) were used for primary cortical neurons cultures according to a modified version of a previously published protocol [15]. Briefly, the cerebral cortex of rats was minced and incubated at $37^{\circ} \mathrm{C}$ for $30 \mathrm{~min}$ in a solution of $2 \mathrm{~g} / \mathrm{l}$ papain. The tissue was washed in medium containing 10\% FBS and then passed through a 400-mesh filter. The dissociated cells were resuspended in complete medium composed of DMEM/F12, 10\% FBS, $100 \mathrm{U} / \mathrm{ml}$ penicillin, and $100 \mathrm{mg} / \mathrm{ml}$ streptomycin, seeded on poly-L-lysine pre-coated plates at a density of $1 \times 10^{5} \mathrm{cells} / \mathrm{cm}^{2}$, and cultured at $37^{\circ} \mathrm{C}$ in humidified atmosphere of $95 \%$ air $/ 5 \% \mathrm{CO}_{2}$. After cell attachment, the medium was replaced with neurobasal medium containing 2\% B27, $0.5 \mathrm{mM}$ glutamine, $100 \mathrm{U} / \mathrm{ml}$ penicillin, and $100 \mathrm{mg} / \mathrm{ml}$ streptomycin, with half of the volume of medium replaced every 2 days thereafter. Arabinosylcytosine $(5 \mu \mathrm{g} / \mathrm{ml})$ was added on day 3 after a 12-h incubation to purify neurons. Cells were used for experiments on day 7 of culture. Experimental procedures were carried out with the approval of the Animal Experimental Committee of Chongqing Medical University, Chongqing, China, and complied with relevant guidelines and laws.

\section{OGD/R model}

The OGD/R model was established according to previously described methods [15] to mimic cerebral artery occlusion and reperfusion injury. Briefly, after three washes with D-Hank's solution, neurons were maintained in D-Hank's solution in a humidified anaerobic incubator (Thermo 3111; Thermo Fisher Scientific, Waltham, MA, USA) in an atmosphere of $94 \% \mathrm{~N}_{2}, 1 \% \mathrm{O}_{2}$, and $5 \% \mathrm{CO}_{2}$ at $37^{\circ} \mathrm{C}$ for $150 \mathrm{~min}$. For reoxygenation, D-Hank's solution was replaced with complete medium composed of neurobasal medium, 2\% B27, $0.5 \mathrm{mM}$ glutamine, $100 \mathrm{U} / \mathrm{ml}$ penicillin, and $100 \mathrm{mg} / \mathrm{ml}$ streptomycin and neurons were incubated in a humidified normoxic atmosphere of $5 \% \mathrm{CO}_{2}$ at $37^{\circ} \mathrm{C}$ for $24 \mathrm{~h}$.

\section{Drug treatment}

To investigate whether resveratrol enhances neuronal viability after OGD/R injury, neuronal cultures were divided into five groups: 1) normal (neurons were cultured in complete medium without OGD/R); 2) control (neurons were subjected to $\mathrm{OGD} / \mathrm{R}$ ); 3) vehicle (neurons were cultured in complete medium containing ethanol [1.3\% v/v] for $24 \mathrm{~h}$ before OGD/R); and 4) resveratrol pretreatment (neurons were cultured in complete medium containing different concentrations [1, 5, and $20 \mu \mathrm{mol} / \mathrm{l}]$ resveratrol for $24 \mathrm{~h}$ before OGD/R); and 5) blank (complete medium without neurons).

To determine whether the protective effects of resveratrol after OGD/R injury were exerted via Shh signaling, neuronal cultures were divided into six groups: 1 ) normal (neurons were cultured in complete medium without OGD/R); 2) control (neurons were cultured in complete medium containing ethanol [1.3\% $\mathrm{v} / \mathrm{v}$ ] for $24 \mathrm{~h}$ before OGD/R); 3) resveratrol (neurons were cultured in complete medium containing 5 $\mu \mathrm{mol} / \mathrm{l}$ resveratrol for $24 \mathrm{~h}$ before OGD/R); 4 ) resveratrol + cyclopamine (neurons were cultured in complete medium containing $5 \mu \mathrm{mol} / \mathrm{l}$ resveratrol and $5 \mu \mathrm{mol} / \mathrm{l}$ cyclopamine for $24 \mathrm{~h}$ before OGD/R); 5) cyclopamine (neurons were cultured in complete medium containing $5 \mu \mathrm{mol} / \mathrm{l}$ cyclopamine for $24 \mathrm{~h}$ before OGD/R); and 6) purmorphamine (neurons were cultured in complete medium containing $3 \mu \mathrm{mol} / \mathrm{l}$ purmorphamine for $24 \mathrm{~h}$ before $\mathrm{OGD} / \mathrm{R})$.

To investigate whether Shh signaling affects Sirt1 activation, neuronal cultures were divided into five groups: 1) normal (neurons were cultured in complete medium without OGD/R); 2) control (neurons were subjected to OGD/R without treatment); 3) resveratrol (neurons were cultured in complete medium containing $5 \mu \mathrm{mol} / \mathrm{l}$ resveratrol for $24 \mathrm{~h}$ before OGD/R); 4) cyclopamine (neurons cultured in complete 


\section{Cellular Physiology Cell Physiol Biochem 2017;43:852-869 \\ \begin{tabular}{ll|l} 
and Biochemistry Published online: September 28, 2017 & $\begin{array}{l}\text { C } 2017 \text { The Author(s). Published by S. Karger AG, Basel } \\
\text { www.karger.com/cpb }\end{array}$ \\
\hline
\end{tabular} \\ Tang et al.: Resveratrol Enhances Neurite Outgrowth and Synaptogenesis Via Activating the Shh Signaling Pathway}

medium containing $5 \mu \mathrm{mol} / \mathrm{l}$ cyclopamine for $24 \mathrm{~h}$ before OGD/R); and 5) purmorphamine (neurons were cultured in complete medium containing $3 \mu \mathrm{mol} / \mathrm{l}$ purmorphamine for $24 \mathrm{~h}$ before OGD/R).

To determine whether Sirt1 activation is associated with Shh signaling, neuronal cultures were divided into four groups: 1) normal (neurons were cultured in complete medium without OGD/R); 2) control (neurons were subjected to OGD/R without treatment); 3) resveratrol (neurons were cultured in complete medium containing $5 \mu \mathrm{mol} / \mathrm{l}$ resveratrol for $24 \mathrm{~h}$ before OGD/R); and 4) sirtinol (neurons were cultured in complete medium containing $10 \mu \mathrm{mol} / \mathrm{l}$ sirtinol for $24 \mathrm{~h}$ before OGD/R).

\section{Cell viability assay}

Neuronal viability was assessed with Cell Counting Kit (CCK)-8. Briefly, primary cortical neurons (approximately 8000/well) were seeded in poly-L-lysine-coated 96-well plates with six replicates per group, and subjected to the above-described treatments. CCK-8 solution $(10 \mu \mathrm{l} / 100 \mu \mathrm{l})$ was added to each culture well and neurons were incubated for $4 \mathrm{~h}$ at $37^{\circ} \mathrm{C}$. Absorbance at $450 \mathrm{~nm}$ was measured with a microplate reader (Thermo Labsystems, Vantaa, Finland). The experiment was repeated four times.

\section{TUNEL assay}

The TUNEL assay was used to detect apoptotic neurons. Briefly, neurons were fixed in $4 \%$ paraformaldehyde for $15 \mathrm{~min}$, washed with phosphate-buffered saline (PBS), then incubated for $1 \mathrm{~h}$ at $37^{\circ} \mathrm{C}$ with anti-fading medium. Neurons were counterstained with anti-MAP2 antibody, and examined under a fluorescence microscope (IX71; Olympus, Tokyo, Japan). The percentage of apoptotic cells was determined by counting the number of cells with nuclear condensation relative to the total number of cells for each experimental condition. The experiment was repeated three times.

\section{Immunocytochemistry}

Neurons were seeded on coverslips coated with poly-L-lysine and fixed with $4 \%$ paraformaldehyde for $30 \mathrm{~min}$ at room temperature, then washed three times with PBS and permeabilized with $0.1 \%$ Triton X-100 for 30 min at room temperature. After three washes with PBS, cells were blocked with 10\% normal goat serum for $30 \mathrm{~min}$ at $37^{\circ} \mathrm{C}$, then incubated overnight at $4^{\circ} \mathrm{C}$ with the following primary monoclonal antibodies: mouse anti-MAP2 (1:100) and anti-TuJ1 (1:200), and rabbit anti-GAP43 (1:200) and antiSYP (1:200). After washes with PBS, cells were incubated with Alexa Fluor 488 goat anti-rabbit or Alexa Fluor 594 goat anti-mouse IgG (1:100) for $1 \mathrm{~h}$ at $37^{\circ} \mathrm{C}$. The primary antibody was replaced with PBS in the negative control. Nuclei were counterstained with DAPI for $5 \mathrm{~min}$ in the dark. Cells were examined with laser confocal microscope (Nikon, Tokyo, Japan). Each experiment was repeated three times.

\section{Western blotting}

To analyze cellular protein levels, primary cortical neurons were rinsed twice with ice-cold PBS, lysed in RIPA lysis buffer containing 1\% PMSF, and incubated on ice for $30 \mathrm{~min}$. After centrifugation at 12, $000 \times g$ and $4^{\circ} \mathrm{C}$ for $10 \mathrm{~min}$, the protein concentration was determined with the bicinchoninic acid assay. Protein samples were mixed with $5 \times$ loading buffer (1:4) and boiled for $10 \mathrm{~min}$, and then resolved by $8 \%$ or $10 \%$ sodium dodecyl sulfate-polyacrylamide gel electrophoresis and transferred to a polyvinylidene difluoride membrane (Millipore, Billerica, MA, USA). The membrane was blocked with 5\% non-fat milk in PBS containing Tween 20 (2:1; PBST) for $2 \mathrm{~h}$ at room temperature and probed overnight at $4{ }^{\circ} \mathrm{C}$ with the following primary antibodies diluted in 5\% non-fat milk in PBST: monoclonal rabbit anti-GAP43 (1:500) and anti-SYP (1:300); monoclonal mouse anti-Sirt1 (1:500); polyclonal rabbit anti-Shh, -Ptch-1, -Smo, and -Gli-1 (1:100); and rabbit anti-GAPDH (1:1000) as a loading control. The membrane was washed with PBST and incubated with peroxidase-conjugated affiniPure goat anti-rabbit or anti-mouse $\operatorname{IgG}$ at $37^{\circ} \mathrm{C}$ for $1 \mathrm{~h}$. Protein bands were detected by enhanced chemiluminescence and their intensities were analyzed with Quantity One software (Bio-Rad, Hercules, CA, USA). The gray ratio of the target protein to GAPDH represented the expression level of the target protein. Each experiment was repeated three times.

\section{Neurite outgrowth and synaptogenesis}

To evaluate the neurite outgrowth and synaptogenesis, images obtained by laser confocal microscopy were analyzed with Image-Pro Plus v.6.0 software (Media Cybernetics, Rockville, MD, USA). Neurite outgrowth was determined by counting the length of axons and number of dendrites. Synaptogenesis were determined by counting the number of synapses per neuron. Values are reported as the mean of at least three independent experiments with samples prepared in triplicate. 


\section{Cellular Physiology and Biochemistry}

Cell Physiol Biochem 2017;43:852-869 \begin{tabular}{l|l}
\hline DOI: $10.1159 / 000481611$ & (C) 2017 The Author(s). Published by S. Karger AG, Base
\end{tabular} Published online: September 28, 2017 www.karger.com/cpb

Tang et al.: Resveratrol Enhances Neurite Outgrowth and Synaptogenesis Via Activating the Shh Signaling Pathway

Fig. 1. Identification of neurons. (a, d) Nuclei were labeled with DAPI (blue). (b) Primary cortical cells from neonatal rats were immunolabeled with an antibody against MAP2 (red). (e) MAP2 antibody was replaced with PBS as a negative control (NC). (c, f) Merged views of panels $\mathrm{a} / \mathrm{b}$ and d/e. Scale bars $=50 \mu \mathrm{m}$.
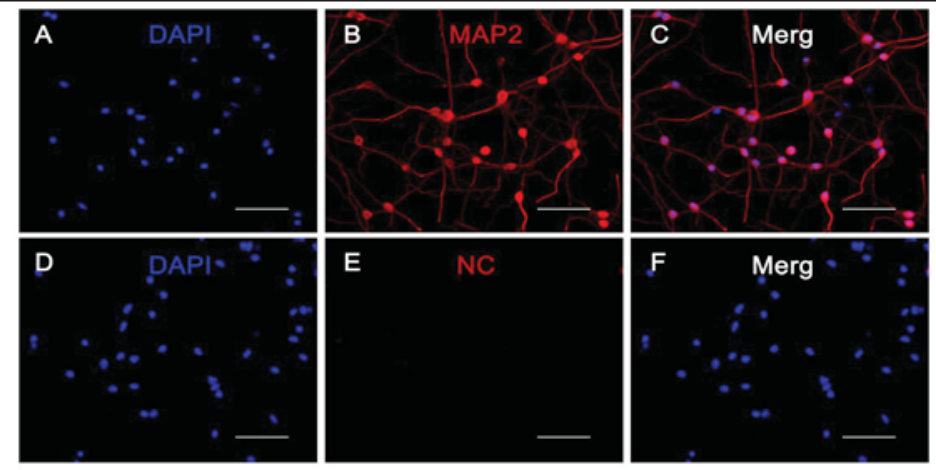

\section{Statistical analysis}

Quantitative data are presented as mean \pm standard deviation. Statistically significant differences between groups were evaluated by one-way analysis of variance followed by Tukey's post hoc test for multiple comparisons and the Student's t test for single comparisons. Data were analyzed using SPSS v.19.0 for Windows. P $<0.05$ was considered statistically significant.

\section{Results}

Identification of primary cortical neurons from neonatal rats

Primary cortical neurons

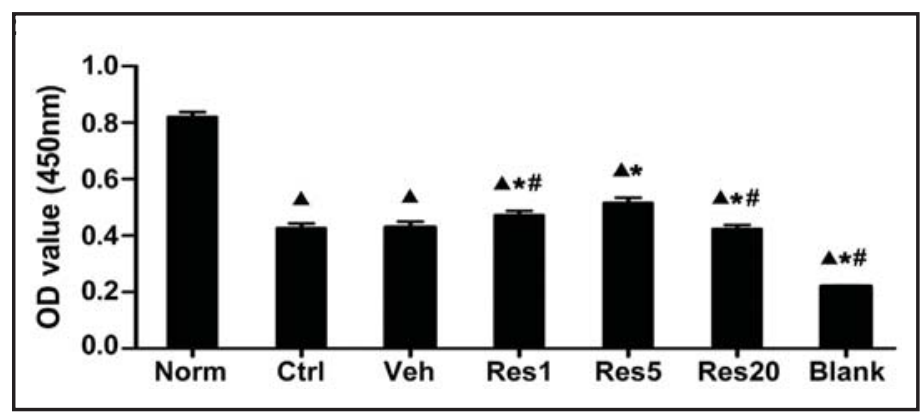

Fig. 2. Resveratrol enhances neuronal viability in a concentrationdependent manner after OGD/R injury in vitro, as determined with the CCK-8 assay. OD values were lower in the control (Ctrl), vehicle (Veh), 1, 5, $20 \mu \mathrm{mol} / \mathrm{l}$ resveratrol (Res 1, Res 5, Res 20), and blank groups relative to the normal (Norm) group. There was no difference between control and vehicle groups. OD values of the resveratrol groups were higher than those in the control and vehicle groups. $\Delta \mathrm{P}<0.05$ vs. Norm; ${ }^{*} \mathrm{P}<0.05$ vs. Ctrl and Veh; $\# \mathrm{P}<0.05$ vs. Res 5 (ANOVA, $\mathrm{n}=4$ per group).

from neonatal rats expressed high levels of MAP2, as determined by immunofluorescence analysis (Fig. 1a-c), confirming their identity as neurons.

Resveratrol enhances the viability of primary cortical neurons following OGD/R injury

The effects of resveratrol pretreatment on neuronal viability following OGD/R injury were investigated with the CCK-8 assay. Viability was decreased in the control $(0.427 \pm$ $0.024)$, vehicle $(0.429 \pm 0.027)$, and 1,5 , and $20 \mu \mathrm{mol} / \mathrm{l}$ resveratrol $(0.472 \pm 0.022,0.515 \pm$ 0.038 , and $0.423 \pm 0.021$, respectively) groups relative to the normal $(0.827 \pm 0.042)$ group (Fig. 2). There was no difference between the control and vehicle groups. Neuronal viability was higher in the resveratrol than in the control and vehicle groups, with the highest rate observed with $5 \mu \mathrm{mol} / \mathrm{l}$ resveratrol treatment. These results indicate that resveratrol attenuates OGD/R injury of primary cortical neurons in a concentration-dependent manner. Since the most effective resveratrol concentration was $5 \mu \mathrm{mol} / \mathrm{l}$, this was used in subsequent experiments.

Shh signaling mediates the effects of resveratrol to enhance neurite outgrowth and synaptogenesis in primary cortical neurons following $O G D / R$ injury in vitro

Our earlier studies showed that resveratrol reduced cerebral ischemic injury and improved neurological function in vivo by inhibiting apoptosis and oxidation [14, 15] and 
Tang et al.: Resveratrol Enhances Neurite Outgrowth and Synaptogenesis Via Activating the Shh Signaling Pathway

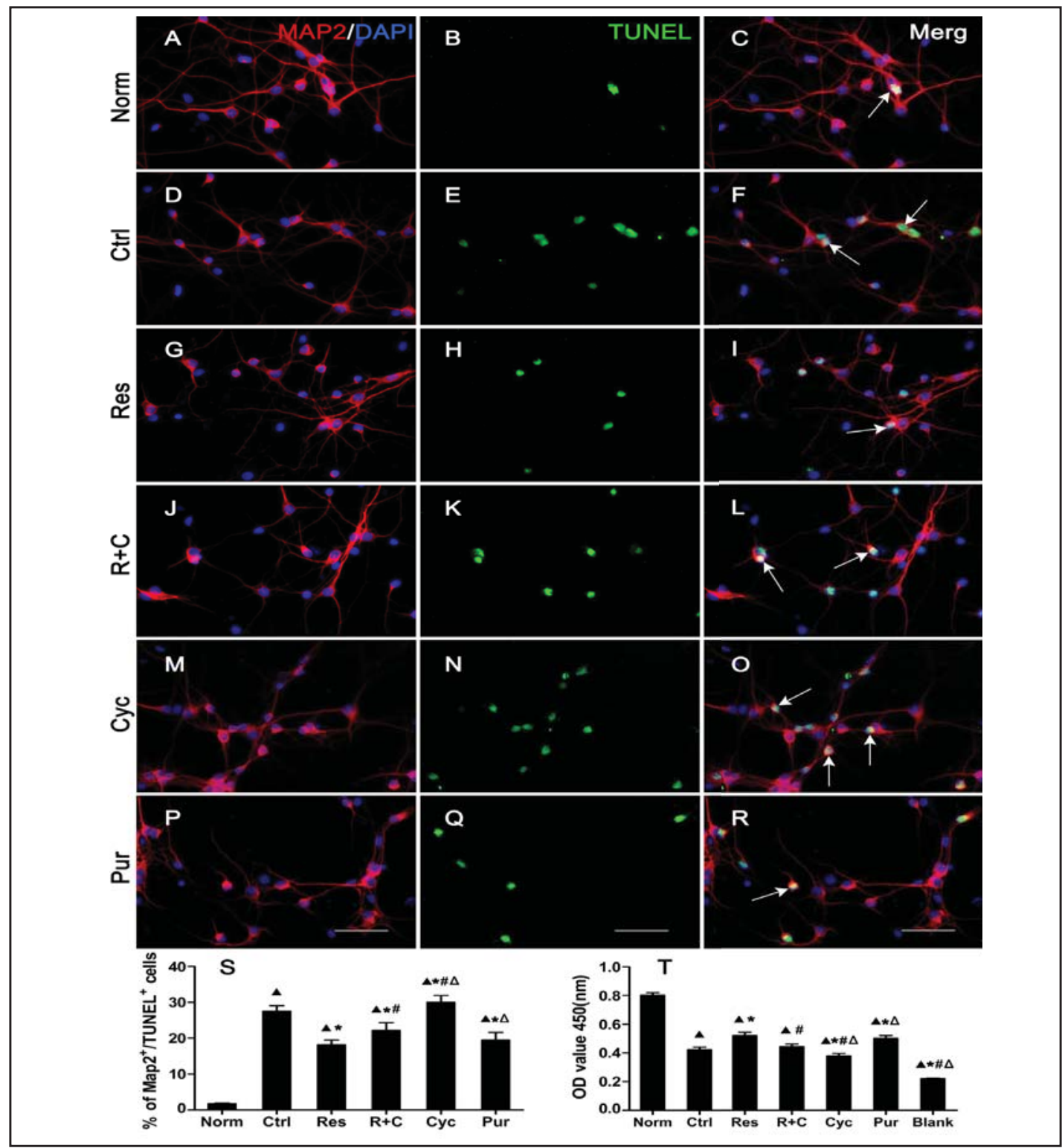

Fig. 3. Cyclopamine abrogates the effects of resveratrol on neuronal viability and apoptosis in primary cortical neurons after OGD/R injury. Viability and apoptosis were evaluated with the CCK-8 and TUNEL assays, respectively. (a-r) Fluorescence micrographs of MAP2+/DAPI+ cells (red/blue) (a, d, g, j, m, p); TUNEL+ cells (green) (b, e, h, k, n, q); and MAP2+/TUNEL+/DAPI+ cells (red/green/blue) (c, f, i, l, o, r) in the Normal (Norm) (a-c), Control (Ctrl) (d-f), resveratrol (Res) (g-i), cyclopamine combined with resveratrol $(\mathrm{R}+\mathrm{C})(\mathrm{j}-\mathrm{l})$, cyclopamine (Cyc) (m-o), and purmorphamine (Pur) (p-r) groups. $(\mathrm{s}, \mathrm{t})$ Quantitative analysis of MAP2+/TUNEL+ cells (s) and viable neurons (t). TUNEL+/MAP2+ cells are apoptotic neurons. $\Delta \mathrm{P}<0.05$ vs. Norm; ${ }^{*} \mathrm{P}<0.05$ vs. Ctrl; $\# \mathrm{P}<0.05$ vs. Res; $\Delta \mathrm{P}<0.05$ vs. $\mathrm{R}+\mathrm{C}$ (ANOVA, $\mathrm{n}=4$ per group). Scale bars $=50 \mu \mathrm{m}$.

stimulating NSC proliferation after OGD/R injury $[16,17]$. Other studies have reported that resveratrol induced neurite outgrowth in Neuro2a cells and rat sensory neurons in vitro $[11,13]$. However, it remains unclear whether resveratrol promotes neurite outgrowth and synaptogenesis. Shh signaling plays an important role in these processes $[18,19]$; we previously demonstrated that it mediated the effects of resveratrol to reduce ischemic cerebral injury and enhance NSC proliferation $[15,17]$. In the present study, we used the Smo inhibitor cyclopamine and Smo agonist purmorphamine to investigate the role of Shh 


\section{Cellular Physiology \\ Cell Physiol Biochem 2017;43:852-869 \\ \begin{tabular}{l|l|l|l} 
DOI: 10.1159/000481611 & ○ 2017 The Author(s). Published by S. Karger AG, Basel \\
\hline
\end{tabular}

Tang et al.: Resveratrol Enhances Neurite Outgrowth and Synaptogenesis Via Activating the Shh Signaling Pathway
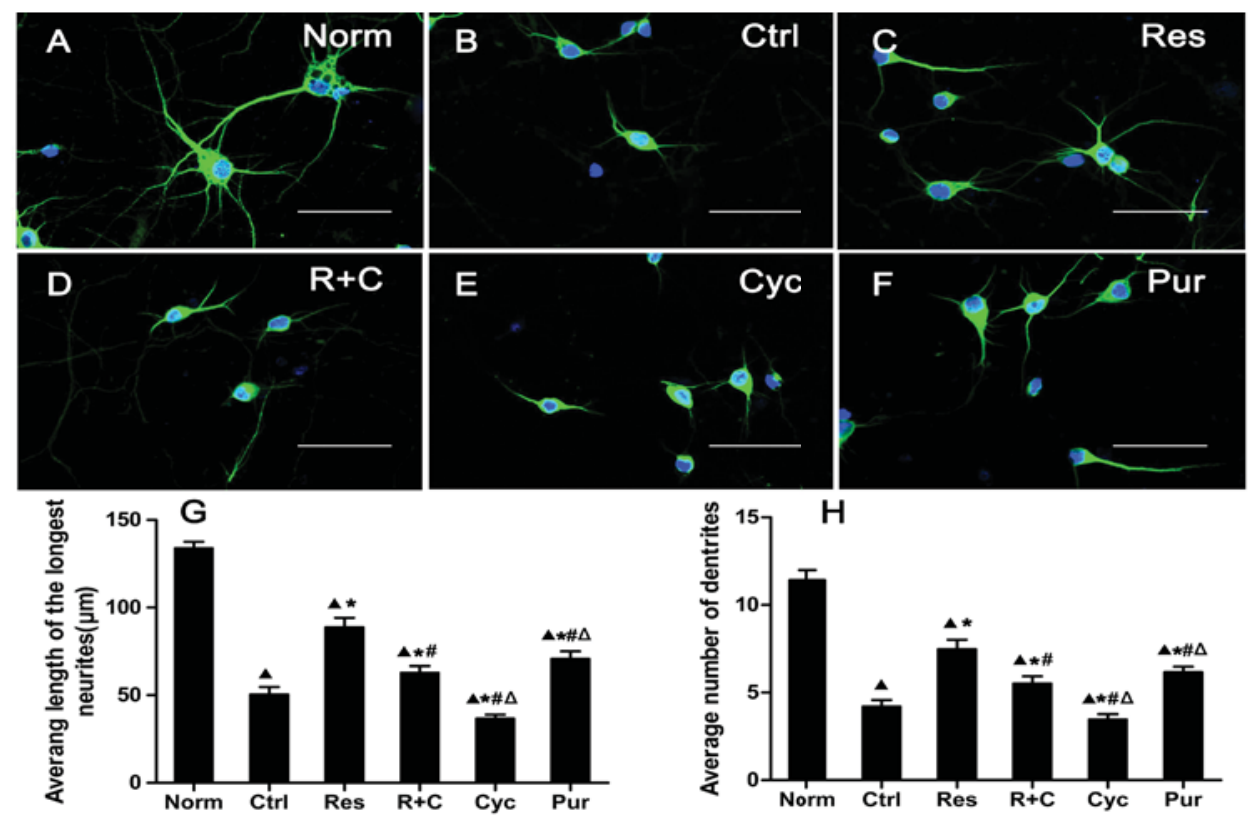

Fig. 4. Cyclopamine inhibits the effects of resveratrol on neurite outgrowth of primary cortical neurons after OGD/R injury in vitro. (a-f) Primary cultured neurons $24 \mathrm{~h}$ after OGD/R in vitro were immunolabeled with antibodies against TuJ1 (green). Nuclei were stained with DAPI (blue). (g, h) Quantitative analysis of neurite length and number. Neurites were long and abundant in the normal group (Norm) (a, g, h). At 24 $\mathrm{h}$ after OGD/R injury, neurite length and number were decreased in the control (Ctrl) as compared to the Norm group (b, g, h). Resveratrol (Res) or purmorphamine (Pur) pretreatment (c, f, g, h) increased neurite number relative to the $\mathrm{Ctrl}$ group. The effects of resveratrol were inhibited in the presence of cyclopamine in the presence of resveratrol $(\mathrm{R}+\mathrm{C})$ or alone $(\mathrm{Cyc})(\mathrm{d}, \mathrm{e}, \mathrm{g}, \mathrm{h})$. Scale bars $=50 \mu \mathrm{m} . \mathbf{\Delta} \mathrm{P}<0.05 \mathrm{vs}$. Norm; ${ }^{*} \mathrm{P}<0.05$ vs. Ctrl; $\# \mathrm{P}<0.05$ vs. Res; $\triangle \mathrm{P}<0.05$ vs. $\mathrm{R}+\mathrm{C}$ (ANOVA, $\mathrm{n}=10$ per group).

signaling in resveratrol-induced neurite outgrowth and synaptogenesis in primary cortical neurons following OGD/R injury.

We first evaluated the effects of resveratrol, cyclopamine, and purmorphamine on the viability of primary cortical neurons after ODG/R injury with the CCK-8 assay. Neurons in the control group decreased viability relative to the normal group $(0.423 \pm 0.018 \mathrm{vs} .0 .803 \pm$ $0.039, \mathrm{P}=0.0001$ ) (Fig. 3t). Pretreatment with resveratrol or purmorphamine increased cell viability relative to the control group $(0.520 \pm 0.024, \mathrm{P}=0.008$ and $0.504 \pm 0.018, \mathrm{P}=0.013$, respectively), although there was no difference between the resveratrol and purmorphamine groups $(\mathrm{P}=0.490)$. However, the effects of resveratrol on neuronal viability were inhibited in neurons cultured with cyclopamine alone $(0.402 \pm 0.017, \mathrm{P}=0.003)$ or cyclopamine combination with resveratrol $(0.443 \pm 0.016, \mathrm{P}=0.026)$. These results indicate that Shh signaling mediates the protective effects of resveratrol on neurons.

We next tested whether resveratrol, cyclopamine, or purmorphamine pretreatment affects apoptosis of primary cortical neurons after ODG/R injury with the TUNEL assay. TUNEL-positive cells were considered as apoptosis (Fig. 3a-r, s). Double labeling for TUNEL and MAP2 revealed apoptotic primary cortical neurons induced by ODG/R injury (Fig. 3a-r); the percentage of TUNEL+/MAP2+ cells was low in the normal group $(1.71 \pm 0.18)$ (Fig. $3 \mathrm{a}-\mathrm{c}, \mathrm{s})$ and higher in the control group $(27.49 \pm 1.55, \mathrm{P}=0.000)$ as compared to the normal group $24 \mathrm{~h}$ after $\mathrm{ODG} / \mathrm{R}$. After resveratrol or purmorphamine pretreatment, the percentage of TUNEL+/MAP2+ cells $(18.15 \pm 1.31, \mathrm{P}=0.010 ; 19.83 \pm 2.10, \mathrm{P}=0.037$, respectively $)$ was decreased relative to the control group, with no difference between the resveratrol and purmorphamine groups $(\mathrm{P}=0.610)$ (Fig. $3 \mathrm{~g}-\mathrm{i}, \mathrm{p}-\mathrm{s})$. However, cyclopamine combined with resveratrol $(22.14 \pm 2.18, \mathrm{P}=0.042)$ (Fig. $3 \mathrm{p}$ ) or cyclopamine alone $(29.98 \pm 1.88, \mathrm{P}=0.007)$ 


\section{Cellular Physiology Cell Physiol Biochem 2017;43:852-869

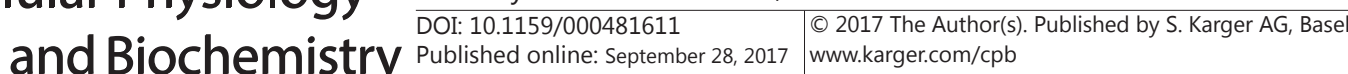 \\ Tang et al.: Resveratrol Enhances Neurite Outgrowth and Synaptogenesis Via Activating the Shh Signaling Pathway}

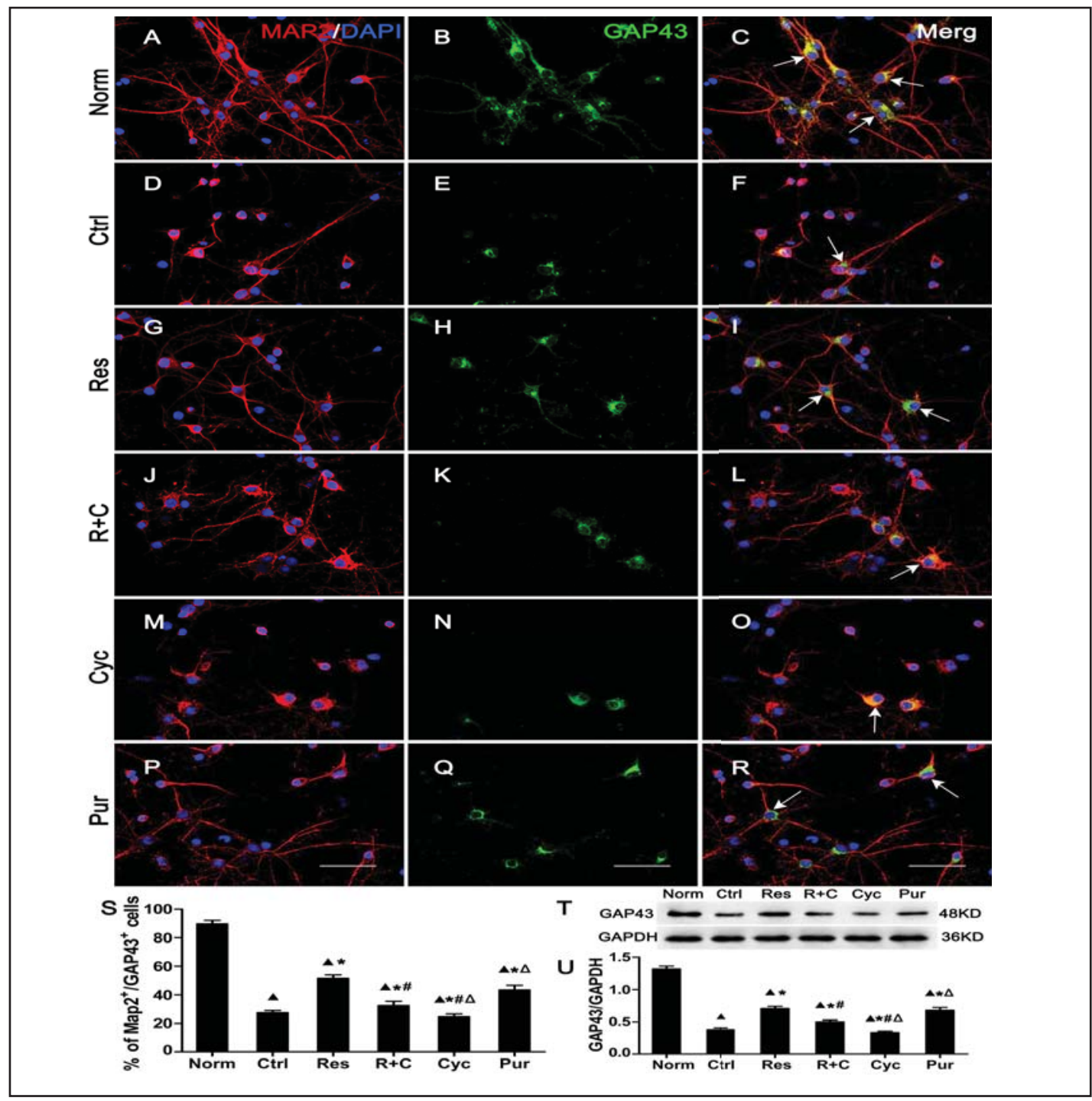

Fig. 5. Cyclopamine inhibits the effect of resveratrol on GAP43 expression after OGD/R injury in primary cortical neurons. (a-r) Fluorescence micrographs of MAP2+/DAPI+ cells (red/blue) (a, d, g, j, m, p); GAP43+ cells (green) (b, e, h, k, n, q); and MAP2+/GAP43+/DAPI+ cells (red/green/blue) (c, f, i, l, o, r) Normal (Norm) (a-c), Control (Ctrl) (d-f), resveratrol (Res) (g-i), cyclopamine combined with resveratrol $(\mathrm{R}+\mathrm{C})(\mathrm{j}-$ l), cyclopamine (Cyc) (m-o), and purmorphamine (Pur) (p-r) groups. (s) Quantitative analysis of MAP2+/ GAP43+/DAPI+ cells. (t) GAP43 protein expression, as detected by western blotting. (u) Quantitative analysis of GAP43 levels. Scale bars $=50 \mu \mathrm{m} . \Delta \mathrm{P}<0.05$ vs. Norm; ${ }^{*} \mathrm{P}<0.05$ vs. Ctrl; $\# \mathrm{P}<0.05$ vs. Res; $\triangle \mathrm{P}<0.05$ vs. $\mathrm{R}+\mathrm{C}$ (ANOVA, $\mathrm{n}=3$ per group).

(Fig. 3q) abolished the effects of resveratrol. Moreover, neurons treated with cyclopamine alone showed the highest fraction of TUNEL+/MAP2+ cells. These results confirm that Shh signaling mediates the neuroprotective effects of resveratrol after ODG/R injury.

We then investigated whether resveratrol, cyclopamine, and purmorphamine treatment affected neurite outgrowth in primary cortical neurons after OGD/R injury. Neurons were labeled with anti-TuJ1 antibody (Fig. 4a-f) and the number and length of neurites were quantified (Fig. 4g, h). Neurons in the normal group had long and abundant neurites (133.76 $\pm 3.80 \mu \mathrm{m}$ and $11.42 \pm 0.56$, respectively) (Fig. $4 \mathrm{a}, \mathrm{g}$, h). At $24 \mathrm{~h}$ after OGD/R injury, neurite length and number were decreased in the control relative to the normal group $(50.49 \pm 4.13$ 
Tang et al.: Resveratrol Enhances Neurite Outgrowth and Synaptogenesis Via Activating the Shh Signaling Pathway

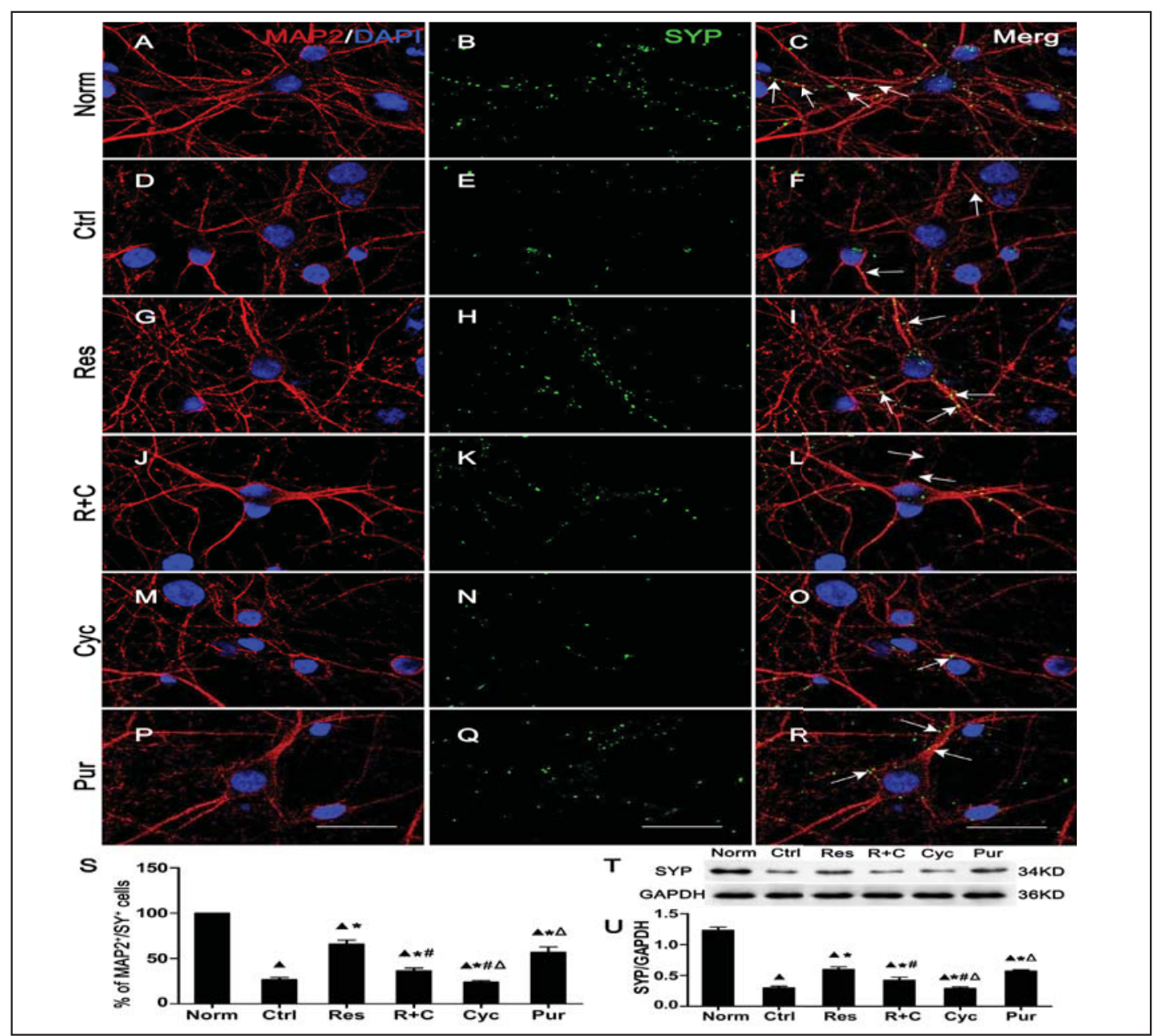

Fig. 6. Cyclopamine abolishes the effect of resveratrol on SYP expression after OGD/R injury in primary cortical neurons. (a-r) Fluorescence micrographs of MAP2+/DAPI+ cells (red/blue) (a, d, g, j, m, p); SYP+ cells (green) (b, e, h, k, n, q); and MAP2+/SYP+/DAPI+ cells (red/green/blue) (c, f, i, l, o, r) Normal (Norm) $(a-c)$, Control (Ctrl) $(d-f)$, resveratrol (Res) $(g-i)$, cyclopamine combined with resveratrol $(R+C)(j-l)$, cyclopamine (Cyc) (m-o), and purmorphamine (Pur) (p-r) groups. Quantitative analysis of MAP2+/SYP+/ DAPI+ cells. ( $\mathrm{t}$ ) SYP protein expression, as detected by western blotting. (u) Quantitative analysis of SYP levels. $\Delta \mathrm{P}<0.05$ vs. Norm; ${ }^{*} \mathrm{P}<0.05$ vs. Ctrl; $\# \mathrm{P}<0.05$ vs. Res; $\triangle \mathrm{P}<0.05$ vs. $\mathrm{R}+\mathrm{C}$ (ANOVA, $\mathrm{n}=3$ per group). Scale bars $=25 \mu \mathrm{m}$.

$\mu \mathrm{m}, \mathrm{P}=0.000$ and $4.20 \pm 0.38, \mathrm{P}=0.0001$, respectively) (Fig. 4b, g, h). Pretreatment with resveratrol or purmorphamine rescued the decreases in neurite length and number (length: $88.82 \pm 5.40 \mu \mathrm{m}, \mathrm{P}=0.005$ and $70.83 \pm 4.24 \mu \mathrm{m}, \mathrm{P}=0.026$, respectively; number: $7.48 \pm 0.54$, $\mathrm{P}=0.008$ and $6.17 \pm 0.32, \mathrm{P}=0.017$, respectively) as compared to the control group (Fig. $4 \mathrm{c}, \mathrm{f}-\mathrm{h})$, with the values in the purmorphamine group lower than those in the resveratrol group $(\mathrm{P}=0.020)$. However, the effects of resveratrol on neurite length and number were suppressed by treatment with cyclopamine alone $(36.65 \pm 2.28 \mu \mathrm{m}, \mathrm{P}=0.000$ and $3.47 \pm$ $0.31, \mathrm{P}=0.003$, respectively) or cyclopamine combined with resveratrol $(62.80 \pm 3.89 \mu \mathrm{m}, \mathrm{P}$ $=0.017$ and $5.52 \pm 0.42, \mathrm{P}=0.045$, respectively) (Fig. $4 \mathrm{~d}, \mathrm{e}, \mathrm{g}, \mathrm{h}$ ). Moreover, neurons treated with cyclopamine alone had the shortest and fewest neurites. These results indicate that resveratrol promotes neurite outgrowth via Shh signaling.

GAP43 is a marker of axonal regeneration and synaptic plasticity [32,33], while SYP is a synaptic protein [34]. To investigate whether resveratrol, cyclopamine, or purmorphamine pretreatment affect synaptogenesis, we examined the expression of GAP-43 and SYP after 
Tang et al.: Resveratrol Enhances Neurite Outgrowth and Synaptogenesis Via Activating the Shh Signaling Pathway

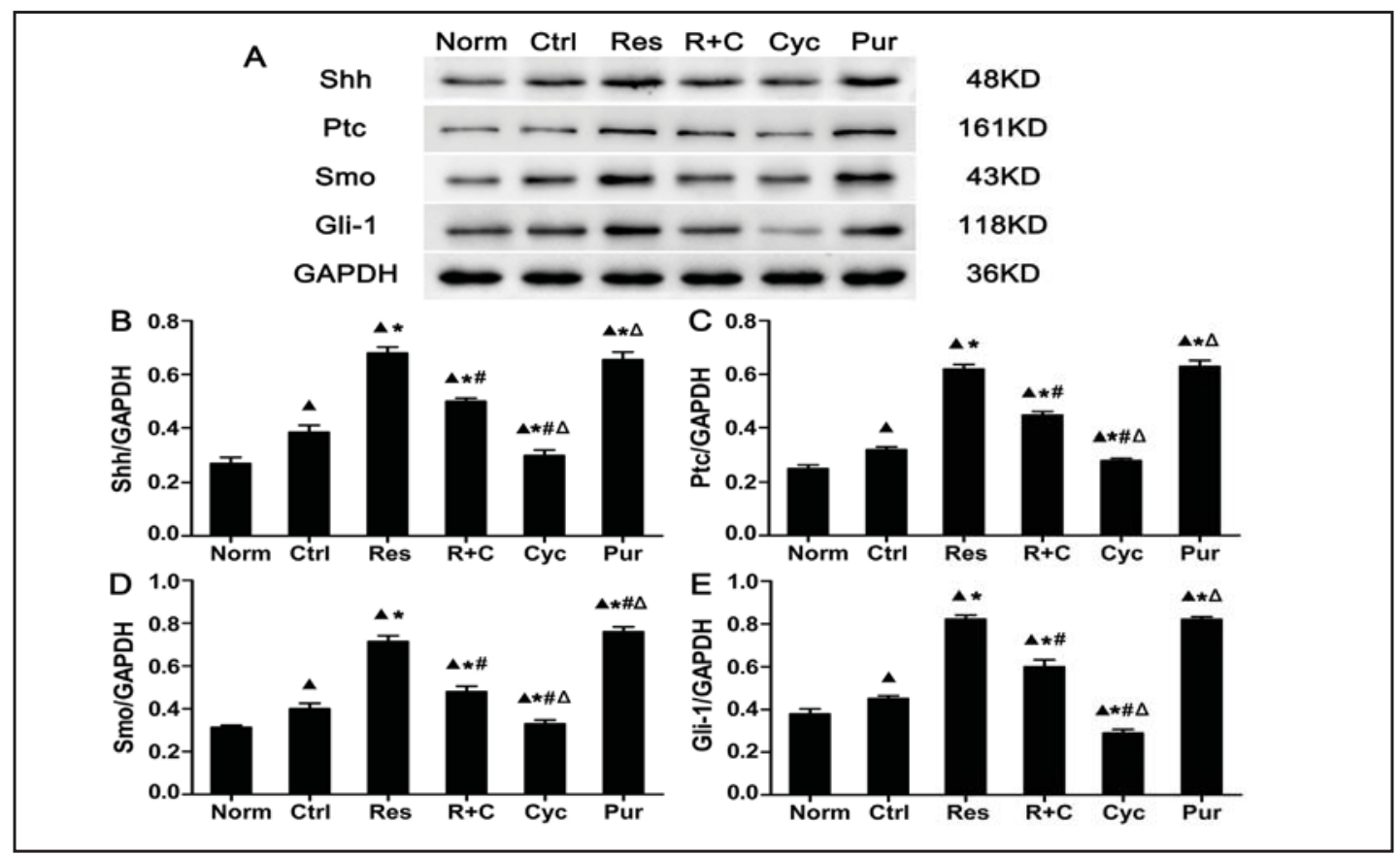

Fig. 7. Cyclopamine abrogates the effects of resveratrol on Shh, Ptc-1, Smo, and Gli-1 expression after OGD/R injury in primary cortical neurons. (a) Sh, Ptc-1, Smo, and Gli-1 protein levels, as detected by western blotting. (b-e) Quantitative analysis of Shh, Ptc-1, Smo, and Gli-1 levels. All four proteins were upregulated in the control (Ctrl), resveratrol (Res), cyclopamine combined with resveratrol $(\mathrm{R}+\mathrm{C})$, and purmorphamine (Pur) relative to the normal (Norm) group. $\Delta \mathrm{P}<0.05$ vs. Norm; ${ }^{*} \mathrm{P}<0.05$ vs. Ctrl; $\# \mathrm{P}<0.05$ vs. Res; $\triangle \mathrm{P}<0.05$ vs. $\mathrm{R}+\mathrm{C}$ (ANOVA, $\mathrm{n}=3$ per group).

OGD/R injury by immunofluorescence analysis. The percentages of GAP43+/MAP2+ and SYP+/MAP2+ neurons in the control $(27.50 \pm 1.55, \mathrm{P}=0.000$ and $26.81 \pm 2.39$, respectively) (Figs. 5 and $6 \mathrm{f}, \mathrm{s})$, resveratrol ( $51.49 \pm 2.39, \mathrm{P}=0.000$ and $65.83 \pm 4.48$, respectively) (Figs. 5 and $6 \mathrm{i}, \mathrm{s})$, cyclopamine + resveratrol $(32.47 \pm 3.01, \mathrm{P}=0.000$ and $36.47 \pm 3.01$, respectively) (Figs. 5 and $61, \mathrm{~s})$, cyclopamine $(24.65 \pm 2.01, \mathrm{P}=0.000$ and $23.98 \pm 1.70$, respectively) (Figs. 5 and $60, \mathrm{~s})$, and purmorphamine (43.49 $\pm 3.22, \mathrm{P}=0.000$ and $56.86 \pm 5.89$, respectively) (Figs. 5 and $6 \mathrm{r}, \mathrm{s}$ ) groups at $24 \mathrm{~h}$ after OGD/R injury were decreased relative to the normal group (89.72 \pm 2.39 ) (Figs. 5 and 6c, s). However, the fractions of GAP43+/MAP2+ and SYP+/MAP2+ neurons were higher in the resveratrol and purmorphamine as compared to the control group (resveratrol: $\mathrm{P}=0.001$ and 0.011 ; purmorphamine: $\mathrm{P}=0.002$ and 0.009 ), although there were no differences between these two treatments $(P=0.117$ and 0.292). When neurons were treated with cyclopamine combined with resveratrol or purmorphamine, the percentages of GAP43+/MAP2+ and SYP+/MAP2+ cells were decreased relative to the control, resveratrol, and purmophamine groups (cyclopamine+resveratrol: $\mathrm{P}=0.008$ and 0.001; cyclopamine+purmorphamine: $\mathrm{P}=0.006$ and 0.001 ). The lowest percentages were observed in the cyclopamine alone group.

A western blot analysis revealed that GAP-43 and SYP expression was increased in the resveratrol and purmorphamine groups and decreased in cyclopamine-treated cells (with or without resveratrol) relative to the control group. There were no differences in protein levels between resveratrol and purmophamine, and the levels were lowest in cells treated with cyclopamine alone (Figs. 5 and $6 \mathrm{t}, \mathrm{u}$ ). These results demonstrate that activation of Shh signaling by resveratrol following ODG/R injury induces the expression of proteins involved in synaptogenesis.

We investigated whether resveratrol pretreatment activated Shh signaling in neurons after ODG/R injury by western blotting. Shh, Ptc-1, Smo, and Gli-1 levels were higher in the 


\section{Cellular Physiology \\ Cell Physiol Biochem 2017;43:852-869 \\ \begin{tabular}{ll|l} 
and Biochemistry Published online: September 28, 2017 & $\begin{array}{l}\text { @ 2017 The Author(s). Published by S. Karger AG, Basel } \\
\text { www.karger.com/cpb }\end{array}$ \\
\hline
\end{tabular} \\ Tang et al.: Resveratrol Enhances Neurite Outgrowth and Synaptogenesis Via Activating the Shh Signaling Pathway}

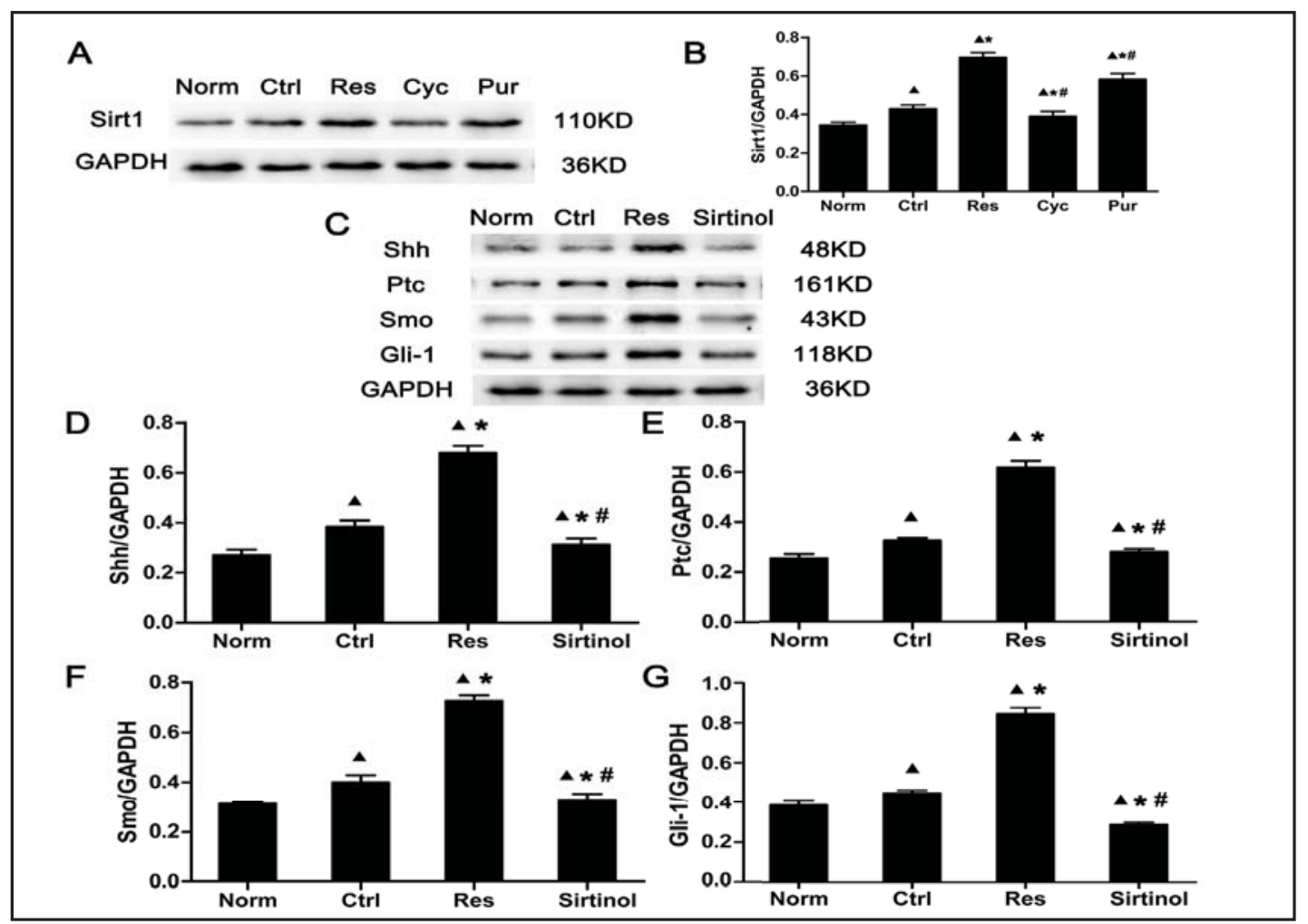

Fig. 8. Interaction between the Shh signaling pathway and Sirt1. (a) Sirt1 expression in neurons pretreated with resveratrol (Res), purmophamine (Pur), or cyclopamine (Cyc), as determined by western blotting after OGD/R injury. (b) Quantitative analysis of Sirt1 protein level. (c) Shh, Ptc-1, Smo, and Gli-1 expression in neurons pretreated with sirtinol. (d-g) Quantitative analysis of Shh, Ptc-1, Smo, and Gli-1 protein levels. $\Delta \mathrm{P}<0.05$ vs. Norm; ${ }^{*} \mathrm{P}<0.05$ vs. Ctrl; $\# \mathrm{P}<0.05$ vs. Res (ANOVA, $\mathrm{n}=3$ per group).

control, resveratrol, cyclopamine + resveratrol, and purmorphamine groups as compared to the normal group $(\mathrm{P}<0.05$; Fig. 7). There were no differences between the resveratrol and purmophamine groups, and the protein levels were highest in the former and lowest in the cyclopamine group. In contrast, the levels were decreased by cyclopamine treatment in the presence or absence of resveratrol as compared to the resveratrol and purmorphamine groups. These results confirm that Shh signaling is activated by resveratrol after OGD/R injury.

\section{Interaction between Shh signaling and Sirt1}

We have previously shown that resveratrol can decrease ischemic cerebral injury; promote neuronal survival, neurite outgrowth, and synaptogenesis; enhance proliferation of NSCs, and induce neuronal differentiation of bone mesenchymal stem cells by activating Shh signaling $[15,17,23]$. Resveratrol is a small-molecule activator of Sirt1; many studies have linked the health benefits of resveratrol to modulation of Sirt1 activity [29, 30]. We therefore examined whether Shh signaling interacts with Sirt1 to mediate the effects of resveratrol. At $24 \mathrm{~h}$ after OGD/R injury, Sirt1 expression was upregulated in the control as compared to the normal group (Fig. 8a, b). Resveratrol or purmorphamine pretreatment increased Sirt1 expression, which was higher in the resveratrol than in the purmorphamine group. However, Sirt1 expression was reduced in the cyclopamine as compared to the resveratrol and purmophamine groups. These results demonstrate that activation of Shh signaling alters Sirt1 expression. We also found that inhibiting Sirt1 with sirtinol reduced the protein levels of Shh, Ptc-1, Smo, and Gli-1 relative to the control and resveratrol groups (Fig. 8c, g). These 


\section{Cellular Physiology Cell Physiol Biochem 2017;43:852-869

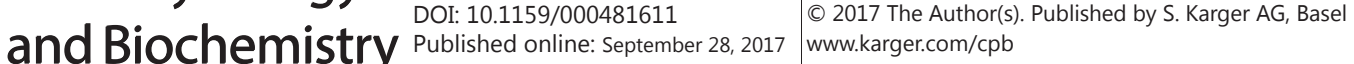 \\ Tang et al.: Resveratrol Enhances Neurite Outgrowth and Synaptogenesis Via Activating the Shh Signaling Pathway}

results indicate that the therapeutic effects of resveratrol following OGD/R injury are exerted by Sirt 1 via activation of the Shh signaling pathway.

\section{Discussion}

The results of the present study showed that resveratrol pretreatment increased viability, reduced apoptosis, and enhanced neurite outgrowth and synaptogenesis of neurons after ODG/R injury in vitro. These effects were mediated via activation of Shh signaling and were abolished by treatment with cyclopamine, a Smo receptor inhibitor. Conversely, activation of Shh signaling by purmophamine, a Smo receptor agonist, produced effects similar to resveratrol. In addition, resveratrol and purmophamine increased, whereas cyclopamine decreased, Sirt1 protein expression. Sirtinol, a Sirt1 inhibitor, suppressed the expression of Shh, Ptc-1, Smo, and Gli-1. Taken together, these findings provide evidence that resveratrol decreases neuronal injury and promotes neurite outgrowth and synaptogenesis following OGD/R injury in vitro via activation of Shh signaling and Sirt1, and Shh may interact with Sirt1.

It was previously reported that $10 \mu \mathrm{M}$ resveratrol induced neurite outgrowth in Neuro2a cells via activation of AMP kinase (AMPK) [13]. Others have found that 10 and 20 $\mu \mathrm{M}$ resveratrol enhanced nerve growth factor-induced neurite outgrowth in PC12 cells via Sirt1 activation [35]. Similar findings were reported in cultured diabetic neurons treated with $0.1-3 \mu \mathrm{M}$ resveratrol, whereas $5 \mathrm{mg} / \mathrm{kg}$ resveratrol reversed thermal hypoalgesia and prevented intraepidermal nerve fiber loss in streptozotocin-induced diabetic rats by increasing AMPK expression and phosphorylation and improving mitochondrial function [11]. Resveratrol also restored the inhibitory effects of microglial over-activation on dendrite sprouting and outgrowth of hippocampal neurons [36]. Our present study showed that 5 $\mu \mathrm{M}$ resveratrol pretreatment promoted neurite outgrowth and synaptogenesis in primary OGD/R injury cortical neurons via activation of the Shh signaling pathway. However, $5 \mu \mathrm{M}$ resveratrol did not prevent amyloid- $\beta$-induced neurotoxicity or enhance neurite outgrowth in N2a cells [12], and failed to restore neurite outgrowth defects in Survival of motor neurondeficient PC12 cells [37]. These studies indicate that the effects of resveratrol on neurite outgrowth vary according to physiological or pathological state.

Although growthing reports and our studies showed that resveratrol has neuroprotective or neurorestorative effects, the mechanism of how resveratrol promotes neurite outgrowth and synaptogenesis is unknown but is important understand in order to manipulate the neurite outgrowth microenvironment to enhance repair and regeneration.

Shh signaling plays a critical role in embryonic development and central nervous system patterning. It is also required for neurite outgrowth, axon guidance, and synaptogenesis in the developing, postnatal, and adult brains. Shh signaling is only activated in the normal adult nervous system in disorders such as stroke [20-22, 38-40], Parkinson's disease [41], multiple sclerosis [42], amyotrophic lateral sclerosis (ALS) [43-55], Huntington's disease (HD) [46], Alzheimer's disease [47, 48], traumatic brain, spinal cord, or peripheral nerve traumatic injury [49-52], subarachnoid hemorrhage [53], and epilepsy [54, 55]. In cerebral ischemic injury, cerebrolysin, bone marrow stromal cells, and purmorphamine enhance activation of the Shh signaling pathway to promote brain plasticity and functional recovery $[20,22,39]$. On the contrary, cyclopamine treatment aggravated brain damage in acute ischemic stroke [56]. In rat and common marmosets models of Parkinson's disease induced by 6-hydroxydopamine or 1-methyl-4-phenyl-1, 2,3, 6-tetrahydropyridine, Shh mitigated neurotoxicity in nigral dopaminergic neurons, reduced apomorphine- and amphetamineinduced rotation and forelimb akinesia, partly preserved dopaminergic axons in the striatum, and repaired nigrostriatal projections [41]. HB1.F3.0lig2 cells treated with Shh protein and transplanted into L5-L6 spinal in a mouse model of ALS delayed the onset of clinical symptoms and extended lifespan [45]. HD is characterized by neuronal dysfunction and progressive loss of dopamine- and cyclic AMP-regulated neuronal phosphoprotein (DARPP)-32- 


\section{Cellular Physiology Cell Physiol Biochem 2017;43:852-869 \\ \begin{tabular}{ll|l} 
DOI: 10.1159/000481611 & $\begin{array}{l}\text { C } 2017 \text { The Author(s). Published by S. Karger AG, Base } \\
\text { www.karger.com/cpb }\end{array}$ \\
\hline
\end{tabular}}

Tang et al:: Resveratrol Enhances Neurite Outgrowth and Synaptogenesis Via Activating the Shh Signaling Pathway

expressing medium-sized spiny neurons in the striatum; Shh increased human pluripotent stem cell differentiation into striatal projection neurons [57], while purmorphamine induced the differentiation of DARPP-32-positive striatal NSCs via Shh signaling, which was blocked by cyclopamine [46]. Alzheimer's disease is caused by the progressive degeneration of cholinergic neurons in the forebrain; in basal forebrain cultures, Shh increased the number of these neurons [47]. In addition, human embryonic stem cells or induced pluripotent stem cell-derived primitive neuroepithelial cells treated with Shh or purmorphamine and cocultured with human astrocytes differentiated into basal forebrain cholinergic neurons [58]. In a mechanical stretch model of reactive astrogliosis, Shh promoted neurite outgrowth in a concentration-dependent manner, an effect that was inhibited by cyclopamine and activated by oxysterol 20(S)-hydroxycholesterol, both of which modulate Smo activity [59]. In adult dorsal root ganglia neurons, expression of Shh and its receptors was upregulated after axotomy; however, Shh deficiency inhibited axonal outgrowth and branching in cultured adult sensory neurons [50]. Shh has also demonstrated neuroprotective effects following crush injury of the cavernous nerve [49]. Our previous study showed that cyclopamine treatment decreased the viability and proliferation of NSCs following OGD/R injury [17] and increased ischemic cerebral injury after stroke [15]. Thus, our results are consistent with previous reports that activation of Shh signaling plays a critical neuroprotective and neurorestorative role following brain injury.

It remains unclear how resveratrol activates Shh signaling. One possibility is that it increases the expression of Shh or its receptors. However, resveratrol is a activator of Sirt1, and some studies have proposed an allosteric mechanism in which the binding of resveratrol to the $\mathrm{N}$ terminal domain of Sirt1 induces a conformational change that promotes tighter binding between Sirt1 and its substrate [60,61], implying that resveratrol is an isoformselective sirtuin activator. However, another study suggested a substrate-dependent Sirt1 activation mechanism in which resveratrol acts to stabilize protein-substrate interaction rather than as an allosteric modulator [29]. Here, our study for the first time showed that the Smoothened (Smo) agonist purmophamine increased the expression of Sirt1, the Smoothened (Smo) antagonist cyclopamine decreased the expression of Sirt1, and the Sirt1 inhibitor sirtinol decreased the expressions of Shh, Ptc-1, Smo, and Gli-1proteins. Tiberi et al. reported that a Sirt1 complex inhibited the Shh signaling in normal and oncogenic neural development [31]. Kong and Yang et al. show that Notch signaling tunes neural progenitor responses to Shh by regulating trafficking of the Shh receptor Patched1 and downstream effector Smoothened to primary cilia. However, Notch can interact with Sirt1 via Hes1 [62]. Therefore, whether Sirt1 is a downstream or upstream target of the Shh signaling activated by resveratrol, or Sirt1 inhibits or activates the Shh signaling remains to be further determined.

Brain derived-nerve neurotrophic factor (BDNF) is a neurotrophic factor widely distributed in the central and peripheral nervous system. It is shown to promote neuronal growth, survival, and injury repair and plays significant role in neurogenesis and neurodegenerative diseases [63-75]. It was reported that resveratrol can significantly promote the recovery of motor function in rats after cerebral ischemic injury [66], decrease hippocampal damage and improve the cognitive deficits in a rat model of vascular dementia [67], decrease hippocampal apoptosis and promote synaptic plasticity and improve cognitive impairment in streptozotocin-induced diabetic rats [68], which is likely related to the upregulation of the BDNF signaling pathway. Shh is a key regulator of multiple pathways during development and in the adult, the BDNF pathway may be one of several regulated by Shh to promote neurite outgrowth. He et al. reported that Shh promotes neurite outgrowth in primary cortical neurons at least partially through modulating BDNF expression [69]. Zhou et al. reported that gene expression of BDNF was decreased in dopaminergic neurons by crossing DATcre (dopamine transporter) mice with Smo(loxP/loxP) knockout mice [70]. In autism spectrum disorder, there was significant correlation between serum levels of BDNF and Shh [71, 72]. In normal and regenerating cavernous nerves, Shh promote regeneration of cavernous nerves via regulating expression of BDNF [73]. However, Wu et al. reported that preconditioning of primary rat cortical cultures with BDNF induces Shh, which contributes 


\section{Cellular Physiology Cell Physiol Biochem 2017;43:852-869 \\ \begin{tabular}{ll|l} 
DOI: 10.1159/000481611 & (c) 2017 The Author(s). Published by S. Karger AG, Base \\
and Biochemistry
\end{tabular} \\ Tang et al:: Resveratrol Enhances Neurite Outgrowth and Synaptogenesis Via Activating the Shh Signaling Pathway}

to the protective effects of BDNF against mitochondrial inhibitor 3-Nitropropionic acid neurotoxicity $[74,75]$. Therefore, whether BDNF is a downstream or upstream target of the Shh signaling activated by resveratrol, or BDNF inhibits or activates the Shh signaling remains to be further determined.

It was previously reported that resveratrol pretreatment 14 days, 7 days, $48 \mathrm{~h}$, or $2 \mathrm{~h}$ before cerebral ischemic injury could protect against ischemic cerebral injury in vivo [7679]. Resveratrol, administered for 4 days and $2 \mathrm{~h}$ prior to ischemia-reperfusion injury and/or 7 days later in the ileum of rats, had a neuroprotective effect [80]. Treatment with resveratrol at the onset of reperfusion or up to $3 \mathrm{~h}$ and $6 \mathrm{~h}$ or $24 \mathrm{~h}$ or post-acute delivery after reperfusion in rodent cerebral ischemic models also showed neuroprotective or neurorestorative effects [81-85]. Others have reported that resveratrol, added $2 \mathrm{~h}$ before and $24 \mathrm{~h}$ after ionizing radiation, reversed the irradiation-induced decline of neural stem cells in murine hippocampal tissue cultures [86]. Moreover, resveratrol can promote neurite outgrowth and synaptogenesis in Neuro2a cells, primary neurons, Alzheimer's disease neurons, and sensory neurons derived from diabete rats in vitro and prevent axonal degeneration after injury [13, 87-89]. Our previous and present studies also showed that resveratrol pretreatment for 7 days before stroke in vivo or $24 \mathrm{~h}$ before OGD/R injury in vitro has neuroprotective or neurorestorative effects $[14,15]$. These studies indicated that pre-, post, and delayed posttreatment with resveratrol showed neuroprotective or neurorestorative effects. However, there are many questions to be further illuminated. For example, whether does pretreatment with resveratrol, purmophamine and/or cyclopamine already affect neurite outgrowth, the level of GAP43, synaptophysin and Shh signaling molecules before ODG/R and cerebral ischemic injury in vitro and vivo? Can shorter resveratrol pretreatment increase Shh signaling in the neuron in vitro or brain in vivo and will it be neuroprotective or neurorestorative? Do resveratrol also enhance neurite outgrowth and synaptogenesis when administered after OGD/R or ischemic injury in vivo or vitro and will it involve Shh signaling? In the future, we will further investigate above questions.

In summary, the results presented here demonstrate that the Shh signaling pathway mediates, at least partly, the effects of resveratrol to increase viability, prevent apoptosis, and enhance neurite outgrowth and synaptogenesis in neurons following OGD/R injury in vitro. We also provide the first evidence that Shh signaling may act on Sirt1 to exert these effects. However, does resveratrol act directly on Shh or its recepors? Or is the effect of resveratrol on Shh signaling mediated through Sirt1 or BDNF or another mechanism? It is further elaborated in vivo and vitro.

\section{Acknowledgements}

This work was supported by grants from the National Nature Science Foundation of China (grant no. 81671309) and the National Key Clinical Specialties Construction Program of China for Neurology (The First Affiliated Hospital of Chongqing Medical University No [2014].27).

\section{Disclosure Statement}

The authors declare that they have no competing interests.

\section{References}

1 Ueno Y, Chopp M, Zhang L, Buller B, Liu Z, Lehman NL, Liu XS, Zhang Y, Roberts C, Zhang ZG: Axonal outgrowth and dendritic plasticity in the cortical peri-infarct area after experimentalstroke. Stroke 2012;43:2221-2228. 


\section{Cellular Physiology Cell Physiol Biochem 2017;43:852-869 \\ \begin{tabular}{ll|l} 
and Biochemistry & $\begin{array}{l}\text { DOI: 10.1159/000481611 } \\
\text { Published online: September 28, } 2017\end{array}$ & $\begin{array}{l}\text { ○ 2017 The Author(s). Published by S. Karger AG, Basel } \\
\text { www.karger.com/cpb }\end{array}$ \\
\hline
\end{tabular}}

Tang et al.: Resveratrol Enhances Neurite Outgrowth and Synaptogenesis Via Activating the Shh Signaling Pathway

-2 Erdogan CS, Vang 0: Challenges in Analyzing the Biological Effects of Resveratrol. Nutrients 2016;8:353.

-3 Diaz-Gerevini GT, Repossi G, Dain A, Tarres MC, Das UN, Eynard AR: Beneficial action of resveratrol: How and why? Nutrition 2016;32:174-178.

4 Lin HY, Tang HY, Davis FB, Davis PJ: Resveratrol and apoptosis. Ann N Y Acad Sci 2011;1215:79-88.

5 Varoni EM, Lo Faro AF, Sharifi-Rad J, Iriti M: Anticancer Molecular Mechanisms of Resveratrol. Front Nutr 2016;3:8.

6 Singh N, Agrawal M, Doré S: Neuroprotective properties and mechanisms of resveratrol in vitro and in vivo experimental cerebral stroke models. ACS Chem Neurosci 2013;4:1151-1162.

7 Sinha K, Chaudhary G, Gupta YK: Protective effect of resveratrol against oxidative stress in middle cerebral artery occlusion model of stroke in rats. Life Sci 2002;71:655-665

8 Li F, Gong Q, Dong H, Shi J: Resveratrol, a neuroprotective supplement for Alzheimer's disease. Curr Pharm Des 2012;18:27-33.

-9 Jin F, Wu Q, Lu YF, Gong QH, Shi JS: Neuroprotective effect of resveratrol on 6-OHDA-induced Parkinson's disease in rats. Eur J Pharmacol 2008;600:78-82.

10 Bastianetto S, Ménard C, Quirion R: Neuroprotective action of resveratrol. Biochim Biophys Acta 2015;1852:1195-201.

11 Roy Chowdhury SK, Smith DR, Saleh A, Schapansky J, Marquez A, Gomes S, Akude E, Morrow D, Calcutt NA, Fernyhough P: Impaired adenosine monophosphate-activated protein kinase signalling in dorsal root ganglia neurons is linked to mitochondrial dysfunction and peripheral neuropathy in diabetes. Brain 2012;135:1751-1766.

12 Manczak M, Mao P, Calkins MJ, Cornea A, Reddy AP, Murphy MP, Szeto HH, Park B, Reddy PH: Mitochondriatargeted antioxidants protect against amyloid-beta toxicity in Alzheimer's disease neurons. J Alzheimers Dis 2010;20:S609-31.

-13 Dasgupta B, Milbrandt J: Resveratrol stimulates AMP kinase activity in neurons. Proc Natl Acad Sci U S A 2007;104:7217-7222.

14 Ren J, Fan C, Chen N, Huang J, Yang Q: Resveratrol pretreatment attenuates cerebral ischemic injury by upregulating expression of transcription factor Nrf2 and HO-1 in rats. Neurochem Res 2011;36:2352-2362.

15 Yu P, Wang L, Tang F, Zeng L, Zhou L, Song X, Jia W, Chen J, Yang Q: Resveratrol Pretreatment Decreases Ischemic Injury and Improves Neurological Function Via Sonic Hedgehog Signaling After Stroke in Rats. Mol Neurobiol 2017;54:212-226.

-16 Shen C, Cheng W, Yu P, Wang L, Zhou L, Zeng L, Yang Q: Resveratrol pretreatment attenuates injury and promotes proliferation of neural stem cells following oxygen-glucose deprivation/reoxygenation by upregulating the expressions of Nrf2, HO-1 and NQO1 in vitro. Mol Med Rep 2016;14:3646-3654.

17 Cheng W, Yu P, Wang L, Shen C,Song X, Chen J, Tang F, Yang Q: Sonic hedgehog signaling mediates resveratrol to increase proliferation of neural stem cells after oxygen-glucose deprivation/reoxygenation injury in vitro. Cell Physiol Biochem 2015;35:2019-2032.

-18 Ulloa F, Martí E: Wnt won the war: antagonistic role of Wnt over Shh controls dorso-ventral patterning of the vertebrate neural tube. Dev Dyn 2010;239:69-76.

19 Rimkus TK, Carpenter RL, Qasem S, Chan M, Lo HW: Targeting the Sonic Hedgehog Signaling Pathway: Review of Smoothened and GLI Inhibitors. Cancers (Basel) 2016;8:22.

-20 Zhang L, Chopp M, Meier DH, Winter S, Wang L, Szalad A, Lu M, Wei M, Cui Y, Zhang ZG: Sonic hedgehog signaling pathway mediates cerebrolysin improved neurological function after stroke. Stroke 2013;44:1965-1972.

21 Huang SS, Cheng H, Tang CM, NienMW, Huang YS, Lee IH, Yin JH, Kuo TB, Yang CC, Tsai SK, Yang DI: Antioxidative, anti-apoptotic, and pro-angiogenic effects mediate functional improvement by sonic hedgehog against focal cerebral ischemia in rats. Exp Neurol Sep 2013;247:680-688.

-22 Chechneva OV, Mayrhofer F, Daugherty DJ, Krishnamurty RG, Bannerman P, Pleasure DE, Deng W: A Smoothened receptor agonist is neuroprotective and promotes regeneration after ischemic brain injury. Cell Death Dis 2014;5:e1481.

-23 Huang JG, Shen CB, Wu WB, Ren JW,Xu L, Liu S, Yang Q: Primary cilia mediate sonic hedgehog signaling to regulate neuronal-like differentiation of bone mesenchymal stem cells for resveratrol induction in vitro. J Neurosci Res 2014;92:587-596.

24 Sacconnay L, Carrupt PA, Nurisso A: Human sirtuins: Structures and flexibility. J Struct Biol 2016;196:534542. 


\section{Cellular Physiology Cell Physiol Biochem 2017;43:852-869 \\ \begin{tabular}{ll|l} 
and Biochemistry & Dublished online: September 28, 2017 & $\begin{array}{l}\text { O } 2017 \text { The Author(s). Published by S. Karger AG, Basel } \\
\text { www.karger.com/cpb }\end{array}$ \\
\hline
\end{tabular}}

Tang et al.: Resveratrol Enhances Neurite Outgrowth and Synaptogenesis Via Activating the Shh Signaling Pathway

-25 Correia M, Perestrelo T, Rodrigues AS, Ribeiro MF, Pereira SL, Sousa MI, Ramalho-Santos J: Sirtuins in metabolism, stemness and differentiation.Biochim Biophys Acta 2017;1861:3444-3455.

-26 Buler M, Andersson U, Hakkola J: Who watches the watchmen? Regulation of the expression and activity of sirtuins. FASEB J 2016;30:3942-3960

27 Tang BL: Sirtuins as modifiers of Parkinson's disease pathology. J Neurosci Res 2017;95(4):930-942.

28 Koronowski KB, Perez-Pinzon MA: Sirt1 in cerebral ischemia. Brain Circ 2015;1:69-78.

-29 Hou X, Rooklin D, Fang H, Zhang Y: Resveratrol serves as a protein-substrate interaction stabilizer in human SIRT1 activation. Sci Rep 2016;6:38186.

-30 Price NL, Gomes AP, Ling AJ, Duarte FV, Martin-Montalvo A, North BJ, Agarwal B, Ye L, Ramadori G, Teodoro JS, Hubbard BP, Varela AT, Davis JG, Varamini B, Hafner A, Moaddel R, Rolo AP, Coppari R, Palmeira CM, de Cabo R, Baur JA, Sinclair DA: SIRT1 Is Required for AMPK Activation and the Beneficial Effects of Resveratrol on Mitochondrial Function. Cell Metab 2012;15:675-690.

-31 Tiberi L, Bonnefont J, van den Ameele J, Le Bon SD, Herpoel A, Bilheu A, Baron BW, Vanderhaeghen P: A BCL6/BCOR/SIRT1 complex triggers neurogenesis and suppresses medulloblastoma by repressing Sonic Hedgehog signaling.Cancer Cell 2014;26:797-812.

-32 Schaden H, Stuermer CA, Bahr M: GAP-43 immunoreactivity and axon regeneration in retinal ganglion cells of the rat. J Neurobiol 1994;25:1570-1578.

33 Honer WG, Falkai P, Chen C, Arango V, Mann JJ, Dwork AJ: Synaptic and plasticity-associated proteins in anterior frontal cortex in severe mental illness. Neuroscience 1999;91:1247-1255.

-34 Yang H, Standifer KM, Sherry DM: Synaptic protein expression by regenerating adult photoreceptors. J Comp Neurol 2002;443:275-288.

-35 Sugino T, Maruyama M, Tanno M, Kuno A, Houkin K, Horio Y: Protein deacetylase SIRT1 in the cytoplasm promotes nerve growth factor-induced neurite outgrowth in PC12 cells. FEBS Lett 2010;584:2821-2826.

-36 Wang F, Cui N, Yang L, Shi L, Li Q, Zhang G, Wu J, Zheng J, Jiao B: Resveratrol Rescues the Impairments of Hippocampal Neurons Stimulated by Microglial Over-Activation In vitro. Cell Mol Neurobiol. 2015;35:10031015.

-37 Bora-Tatar G, Erdem-Yurter H: Investigations of curcumin and resveratrol on neurite outgrowth: perspectives on spinal muscular atrophy. Biomed Res Int 2014;2014:709108.

-38 Sims JR, Lee SW, Topalkara K, Qiu J, Xu J, Zhou Z, Moskowitz MA: Sonic hedgehog regulates ischemia/ hypoxia-induced neural progenitor proliferation. Stroke 2009;40:3618-3626.

-39 Bambakidis NC, Petrullis M, Kui X, Rothstein B, Karampelas I, Kuang Y, Selman WR, LaManna JC, Miller RH: Improvement of neurological recovery and stimulation of neural progenitor cell proliferation by intrathecal administration of Sonic hedgehog. J Neurosurg 2012;116:1114-1120.

40 Ding X, Li Y, Liu Z, Zhang J, Cui Y, Chen X, Chopp M: The sonic hedgehog pathway mediates brain plasticity and subsequent functional recovery after bone marrow stromal cell treatment of stroke in mice. J Cereb Blood Flow Metab 2013;33:1015-1024.

-41 Zhang Y, Dong W, Guo S, Zhao S, He S, Zhang L, Tang Y, Wang H: Lentivirus-mediated delivery of sonic hedgehog into the striatum stimulates neuroregeneration in a rat model of Parkinson disease. Neurol Sci Dec 2014;35:1931-1940.

42 Zhang J, Zhang ZG, Li Y, Ding X, Shang X, Lu M, Elias SB, Chopp M: Fingolimod treatment promotes proliferation and differentiation of oligodendrocyte progenitor cells in mice with experimental autoimmune encephalomyelitis. Neurobiol Dis 2015;76:57-66.

43 Peterson R, Turnbull J: Sonic hedgehog is cytoprotective against oxidative challenge in a cellular model of amyotrophic lateral sclerosis. J Mol Neurosci 2012;47:31-41.

44 Ma X, Turnbull P, Peterson R, Turnbull J: Trophic and proliferative effects of Shh on motor neurons in embryonic spinal cord culture from wildtype and G93A SOD1 mice. BMC Neurosci 2013;14:119.

45 Lee HJ, Kim KS2, Ahn J, Bae HM, Lim I, Kim SU: Human motor neurons generated from neural stem cells delay clinical onset and prolong life in ALS mouse model. PLoS One 2014;9:e97518.

-46 El-Akabawy G, Medina LM, Jeffries A, Price J, Modo M: Purmorphamine increases DARPP-32 differentiation in human striatal neural stem cells through the Hedgehog pathway. Stem Cells 2011;20:1873-1887.

47 Reilly JO, Karavanova ID, Williams KP, Mahanthappa NK, Allendoerfer KL: Cooperative effects of Sonic Hedgehog and NGF on basal forebrain cholinergic neurons. Mol Cell Neurosci 2002;19:88-96.

48 Hung YH, Chang SH, Huang CT, Yin JH, Hwang CS, Yang LY, Yang DI: Inhibitor of Differentiation-1 and Hypoxia-Inducible Factor-1 Mediate Sonic Hedgehog Induction by Amyloid Beta-Peptide in Rat Cortical 


\section{Cellular Physiology Cell Physiol Biochem 2017;43:852-869 \begin{tabular}{l|l|l}
\hline DOI: 10.1159/000481611 & ( 2017 The Author(s). Published by S. Karger AG, Basel
\end{tabular} and Biochemistry Published online: September 28, 2017 www.karger.com/cpb}

Tang et al.: Resveratrol Enhances Neurite Outgrowth and Synaptogenesis Via Activating the Shh Signaling Pathway

Neurons. Mol Neurobiol 2016;53:793-809.

49 Angeloni N, Bond CW, Harrington D, Stupp S, Podlasek CA: Sonic hedgehog is neuroprotective in the cavernous nerve with crush injury. J Sex Med 2013;10:1240-1250.

-50 Martinez JA, Kobayashi M, Krishnan A, Webber C, Christie K, Guo G, Singh V, Zochodne DW: Intrinsic facilitation of adult peripheral nerve regeneration by the Sonic hedgehog morphogen. Exp Neurol 2015;271:493-505.

51 Lowry N, Goderie SK, Lederman P, Charniga C, Gooch MR, Gracey KD, Banerjee A, Punyani S, Silver J, Kane RS, Stern JH, Temple S: The effect of long-term release of Shh from implanted biodegradable microspheres on recovery from spinal cord injury in mice. Biomaterials 2012;33:2892-2901.

52 Amankulor NM, Hambardzumyan D, Pyonteck SM, Becher OJ,Joyce JA, Holland EC: Sonic hedgehog pathway activation is induced by acute brain injury and regulated by injury-related inflammation. J Neurosci 2009;29:10299-10308.

53 Li T, Zhang J, Liu RY, Lian ZG, Chen XL, Ma L, Sun HM, Zhao YL: The role of the sonic hedgehog signaling pathway in early brain injury after experimental subarachnoid hemorrhage in rats. Neurosci Lett 2013;552:81-86.

54 Fang M, Lu Y, Chen GJ, Shen L, Pan YM, Wang XF: Increased expression of sonic hedgehog in temporal lobe epileptic foci in humans and experimental rats. Neuroscience 2011;182:62-70.

55 Feng S, Ma S, Jia C, Su Y, Yang S, Zhou K, Liu Y, Cheng J, Lu D, Fan L, Wang Y: Sonic hedgehog is a regulator of extracellular glutamate levels and epilepsy. ЕMBO Rep 2016;17:682-694.

-56 Ji H, Miao J, Zhang X, Du Y, Liu H, Li S, Li L: Inhibition of sonic hedgehog signaling aggravates brain damage associated with the down-regulation of Gli1, Ptch1 and SOD1 expression in acute ischemic stroke. Neurosci Lett 2012;506:1-6.

-57 Delli Carri A, Onorati M, Lelos MJ, Castiglioni V, Faedo A, Menon R, Camnasio S, Vuono R, Spaiardi P, Talpo F, Toselli M, Martino G, Barker RA, Dunnett SB, Biella G, Cattaneo E: Developmentally coordinated extrinsic signals drive human pluripotent stem cell differentiation toward authentic DARPP-32+ medium-sized spiny neurons. Development 2013;140:301-312.

58 Hu Y, Qu ZY, Cao SY, Li Q, Ma L, Krencik R, Xu M, Liu Y: Directed differentiation of basal forebrain cholinergic neurons from human pluripotent stem cells. J Neurosci Methods 2016;266:42-49.

59 Berretta A, Gowing EK, Jasoni CL, Clarkson AN: Sonic hedgehog stimulates neurite outgrowth in a mechanical stretch model of reactive-astrogliosis. Sci Rep 2016;6:21896.

-60 Cao D, Wang M, Qiu X, Liu D, Jiang H, Yang N, Xu RM: Structural basis for allosteric, substrate-dependent stimulation of SIRT1 activity by resveratrol. Genes Dev 2015;29:1316-1325.

61 Hubbard BP, Gomes AP, Dai H, Li J, Case AW, Considine T, Riera TV, Lee JE, E SY, Lamming DW, Pentelute BL, Schuman ER, Stevens LA, Ling AJ, Armour SM, Michan S, Zhao H, Jiang Y, Sweitzer SM, Blum CA, Disch JS, Ng PY, Howitz KT, Rolo AP, Hamuro Y, Moss J, Perni RB, Ellis JL, Vlasuk GP, Sinclair DA: Evidence for a common mechanism of SIRT1 regulation by allosteric activators. Science 2013;339:1216-1219.

-62 Kong JH,Yang L, Dessaud E, Chuang K, Moore DM, Rohatgi R, Briscoe J, Novitch BG: Notch activity modulates the responsiveness of neural progenitors to sonic hedgehog signaling. Dev Cell 2015;33:373-387

63 Li M, Wang Y, Wang W, Zou C, Wang X, Chen Q: Recombinant human brain-derived neurotrophic factor prevents neuronal apoptosis in a novel in vitro model of subarachnoid hemorrhage.Neuropsychiatr Dis Treat 2017;13:1013-1021.

64 Kotlęga D, Peda B, Zembroń-Łacny A, Gołąb-Janowska M, Nowacki P: The role of brain-derived neurotrophic factor and its single nucleotide polymorphisms in stroke patients. Neurol Neurochir Pol 2017;51:240-246.

65 Zhao H, Alam A, San CY, Eguchi S, Chen Q, Lian Q Ma D: Molecular Mechanisms of Brain-Derived Neurotrophic Factor in Neuro- protection: Recent Developments. Brain Res 2017;1665:1-21.

66 Shi N, Zhu C, Li L: Rehabilitation Training and Resveratrol Improve the Recovery of Neurological and Motor Function in Rats after Cerebral Ischemic Injury through the Sirt1 Signaling Pathway. Biomed Res Int 2016;2016:1732163

67 Shen D, Tian X, Sang W, Song R: Effect of Melatonin and Resveratrol against Memory Impairment and Hippocampal Damage in a Rat Model of Vascular Dementia. Neuroimmunomodulation 2016;23:318-331.

-68 Tian Z, Wang J, Xu M, Wang Y, Zhang M, Zhou Y: Resveratrol improves cognitive impairment by regulating apoptosis and synaptic plasticity in streptozotocin-induced diabetic rats.Cell Physiol Biochem 2016;40:1670-1677. 


\section{Cellular Physiology Cell Physiol Biochem 2017;43:852-869 \\ \begin{tabular}{ll|l} 
and Biochemistry & Dublished online: September 28, 2017 & $\begin{array}{l}\text { O } 2017 \text { The Author(s). Published by S. Karger AG, Basel } \\
\text { www.karger.com/cpb }\end{array}$ \\
\hline
\end{tabular}}

Tang et al.: Resveratrol Enhances Neurite Outgrowth and Synaptogenesis Via Activating the Shh Signaling Pathway

69 He W, Cui L, Zhang C, Zhang X, He J, Xie Y: Sonic Hedgehog Promotes Neurite Outgrowth of Primary Cortical Neurons Through Up-Regulating BDNF Expression. Neurochem Res 2016;41:687-695.

-70 Zhou X, Pace J, Filichia E, Lv T, Davis B, Hoffer B, Selman W, Luo Y: Effect of the sonic hedgehog receptor smoothened on the survival and function of dopaminergic neurons.Exp Neurol 2016;283:235-245.

71 Halepoto DM, Bashir S, Zeina R, Al-Ayadhi LY: Correlation Between Hedgehog (Hh) Protein Family and Brain-Derived Neurotrophic Factor (BDNF) in Autism Spectrum Disorder (ASD). J Coll Physicians Surg Pak 2015;25:882-885.

72 Al-Ayadhi LY: Relationship between Sonic hedgehog protein, brain-derived neurotrophic factor and oxidative stress in autism spectrum disorders. Neurochem Res 2012;37:394-400.

73 Bond CW, Angeloni N, Harrington D, Stupp S, Podlasek CA: Sonic Hedgehog regulates brain-derived neurotrophic factor in normal and regenerating cavernous nerves. J Sex Med 2013;10:730-737.

74 Wu CL, Chen SD, Hwang CS, Yang DI: Sonic hedgehog mediates BDNF-induced neuroprotection against mitochondrial inhibitor 3-nitropropionic acid. Biochem Biophys Res Commun 2009;385:112-117.

-75 Wu CL, Chen SD, Yin JH, Hwang CS, Yang DI: Erythropoietin and sonic hedgehog mediate the neuroprotective effects of brain-derived neurotrophic factor against mitochondrial inhibition. Neurobiol Dis 2010;40:146-154.

76 Koronowski KB, Dave KR, SaulI, Camarena V, Thompson JW1, Neumann JT, Young JI, Perez-Pinzon MA: Resveratrol preconditioning induces a novel extended window of ischemic tolerance in the mouse brain. Stroke 2015;46:2293-2298.

-77 Narayanan SV, Dave KR, Saul I, Perez-Pinzon MA: Resveratrol preconditioning protects against cerebral ischemic injury via nuclear erythroid 2-related factor 2. Stroke 2015;46:1626-1632.

78 Della-Morte D, Dave KR, DeFazio RA, Bao YC, Raval AP, Perez-Pinzon MA: Resveratrol pretreatment protects rat brain from cerebral ischemic damage via a sirtuin 1-uncoupling protein 2 pathway. Neuroscience 2009;159:993-1002.

79 Sakata Y, Zhuang H, Kwansa H, Koehler RC, Doré S: Resveratrol protects against experimental stroke: putative neuroprotective role of heme oxygenase 1. Exp Neurol 2010;224:325-329.

80 Borges SC, da Silva de Souza AC, Beraldi EJ, Schneider LC, Buttow NC: Resveratrol promotes myenteric neuroprotection in the ileum of rats after ischemia-reperfusion injury. Life Sci 2016;166:54-59.

81 Dong W, Li N, Gao D, Zhen H, Zhang X, Li F: Resveratrol attenuates ischemic brain damage in the delayed phase after stroke and induces messenger RNA and protein express for angiogenic factors. J Vasc Surg 2008;48:709-714.

-82 Tsai SK, Hung LM, Fu YT, Cheng H, Nien MW, Liu HY, Zhang FB, Huang SS: Resveratrol neuroprotective effects during focal cerebral ischemia injury via nitric oxide mechanism in rats. J Vasc Surg 2007;46:346353.

83 Shin JA, Lee H, Lim YK, Koh Y, Choi JH, Park EM: Therapeutic effects of resveratrol during acute periods following experimental ischemic stroke. J Neuroimmunol 2010;227:93-100.

84 Hermann DM, Zechariah A, Kaltwasser B, Bosche B, Caglayan AB, Kilic E, Doeppner TR: Sustained neurological recovery induced by resveratrol is associated with angioneurogenesis rather than neuroprotection after focal cerebral ischemia. Neurohiol Dis 2015;83:16-25.

-85 Feng Y, Cui Y, Gao JL, Li R, Jiang XH, Tian YX, Wang KJ, Li MH, Zhang HA, Cui JZ: Neuroprotective effects of resveratrol against traumatic brain injury in rats: Involvement of synaptic proteins and neuronal autophagy. Mol Med Rep 2016;13:5248-5254.

-86 Prager I, Patties I, Himmelbach K, Kendzia E, Merz F, Müller K, Kortmann RD, Glasow A: Dose-dependent short- and long-term effects of ionizing irradiation on neural stem cells in murine hippocampal tissue cultures: neuroprotective potential of resveratrol. Brain Behav 2016;6:e00548.

87 Sugino T, Maruyama M, Tanno M, Kuno A, Houkin K, Horio Y: Protein deacetylase SIRT1 in the cytoplasm promotes nerve growth factor-induced neurite outgrowth in PC12 cells. FEBS Lett 2010;584:2821-2826.

-88 Manczak M, Mao P, Calkins MJ, Cornea A, Reddy AP, Murphy MP, Szeto HH, Park B, Reddy PH: Mitochondriatargeted antioxidants protect against amyloid-beta toxicity in Alzheimer's disease neurons. J Alzheimers Dis 2010;20:S609-S631.

89 Chen YY, Zhang L, Shi DL, Song XH, Shen YL, Zheng MZ, Wang LL: Resveratrol attenuates subacute systemic inflammation-induced spatial memory impairment via inhibition of astrocyte activation and enhancement of synaptophysin expression in the hippocampus. Ann Clin Lab Sci 2017;47:17-24. 